IZA DP No. 5442

Job Search Requirements for Older Unemployed: Transitions to Employment, Early Retirement and Disability Benefits

Hans Bloemen

Stefan Hochguertel

Marloes Lammers

January 2011 


\title{
Job Search Requirements for Older Unemployed: Transitions to Employment, Early Retirement and Disability Benefits
}

\author{
Hans Bloemen \\ VU University Amsterdam, Tinbergen Institute, Netspar and IZA \\ Stefan Hochguertel \\ VU University Amsterdam, Tinbergen Institute and Netspar \\ Marloes Lammers \\ VU University Amsterdam, Tinbergen Institute and Netspar
}

Discussion Paper No. 5442
January 2011

IZA

P.O. Box 7240

53072 Bonn

Germany

Phone: +49-228-3894-0

Fax: +49-228-3894-180

E-mail: iza@iza.org

Any opinions expressed here are those of the author(s) and not those of IZA. Research published in this series may include views on policy, but the institute itself takes no institutional policy positions.

The Institute for the Study of Labor (IZA) in Bonn is a local and virtual international research center and a place of communication between science, politics and business. IZA is an independent nonprofit organization supported by Deutsche Post Foundation. The center is associated with the University of Bonn and offers a stimulating research environment through its international network, workshops and conferences, data service, project support, research visits and doctoral program. IZA engages in (i) original and internationally competitive research in all fields of labor economics, (ii) development of policy concepts, and (iii) dissemination of research results and concepts to the interested public.

IZA Discussion Papers often represent preliminary work and are circulated to encourage discussion. Citation of such a paper should account for its provisional character. A revised version may be available directly from the author. 
IZA Discussion Paper No. 5442

January 2011

\section{ABSTRACT \\ Job Search Requirements for Older Unemployed: Transitions to Employment, Early Retirement and Disability Benefits}

In this paper, we use a recent policy change in the Netherlands to study how changes in search requirements for the older unemployed affect their transition rates to employment, early retirement and sickness/disability benefits. The reform, becoming effective on January 1st 2004, required the elderly to formally report their job search efforts to the employment office in order to avoid a (temporary) cut in benefits. Before the new law was passed, unemployed were allowed to stop all search activity at the moment they turned 57.5. Estimating various duration models using difference-in-difference and regression discontinuity approaches, we find that for several groups of individuals that were affected by the policy change, the stricter search requirements did significantly increase their entry rate into employment. However, we also find evidence of a higher outflow to sickness/disability insurance schemes, a presumably unwanted side-effect of the policy change.

JEL Classification: $\quad$ C31, J26, J64, J68

Keywords: duration analysis, policy evaluation, search effort, substitution

Corresponding author:

Marloes Lammers

VU University Amsterdam

de Boelelaan 1105

1081 HV Amsterdam

The Netherlands

E-mail: mlammers@feweb.vu.nl

\footnotetext{
* We are grateful for useful comments and suggestions from Jonneke Bolhaar, Marloes de Graaf-Zijl, Jan Rouwendal, Stefan Staubli, Bas van der Klaauw, Karen van der Wiel, participants of seminars at the EALE/SOLE 2010 London, EEA 2010 in Glasgow, the second meeting of the Danish Microeconometric Network, the Centre for research in active labour market policy effects (CAFE) in Aarhus, Netspar (Network for Studies on Pensions, Aging and Retirement) conferences in Gilze-Rijen, Utrecht and Zurich, and seminars at the Tinbergen Institute, the Netherlands Bureau for Economic Policy Analysis and the IAB in Nuremberg. All remaining errors are our own. This paper previously circulated under the name: "The effects of job search requirements for the older unemployed".
} 


\section{Introduction}

How can policy be successful in keeping older workers attached to the labor market? This question is central to policy reforms involving an outward shift of retirement age to 67 and beyond, as is being discussed or implemented in many countries. One important aspect of increasing the labor market participation of older individuals is to get them back to work after a period of unemployment. However, little is known about the labor market behavior of this growing age class. In particular job search behavior and its relation to financial incentives are not well documented. This state of affairs is peculiar since inflow rates of older workers into unemployment are typically higher than those of prime-aged employees. Outflow rates back into employment are, on the other hand, remarkably low. It is well documented that a job loss results in large and lasting effects on future employment probabilities of older workers, for example in the U.S (Chan and Stevens (2001)) and in the Netherlands (de Graaf-Zijl and Hop (2007)).

This paper exploits a recent policy change in the Netherlands to examine how changes in search requirements for the older unemployed affect their transition rates to employment, retirement and disability benefits. Before January 1st 2004, older unemployed (defined as being at least 57.5 years old) were not required to actively search for a job in order to receive full UI benefits. After that date, the $57.5+$ year-olds faced the same regulations as other age groups and needed to report their (formal) search behaviour to the unemployment office.

To study labor market transitions of older workers, access to a dataset with a large cross sectional dimension is needed. Labor market surveys are usually based on a representative sample of the entire working age population and only a tiny fraction of older unemployed individuals is observed, precluding meaningful analyses of transition behavior for this group. The present paper contributes to filling this gap by using a large administrative database covering all registered benefit and wage receipts in the Netherlands, including all individuals on UI benefits. The data provides very precise information on income and labor market status, giving us a large enough sample to analyze labor market transitions of the older unemployed in the years 2001 to 2005 .

This study is related to the large strand of literature examining the effects of changes in the UI benefit system on unemployment duration. Most of these papers are concerned with effects of sanctions or training programs (Abbring et al. (2005), van den Berg et al. (2004), van den Berg and van der Klaauw (2006)), changes in potential benefit duration (Caliendo et al. (2009), Card and Levine (2000), Kyyrä and Ollikainen (2008), Lalive et al. (2006), Lalive (2008), van Ours and Vodopivec (2006)) or the level or replacement rate of unemployment benefits (Carling et. al. (2001), Røed and Zhang (2003)). Studies examining a tightening of search requirements are less widespread. Manning (2009) finds large flows out of claimant status upon a tightening of search requirements in the U.K but does not find an effect on search intensity. Petrongolo (2009), studying the same U.K. reform, concludes that although unemployment duration has decreased, the outflow to disability insurance benefits increased, indicating that some individuals decided to stop searching and to enter other social insurance schemes instead. Our paper is closest to Heyma and van 
Ours (2005), who examine the effect of a discontinuity in UI eligibility criteria for the Dutch elderly. They find a substantially lower outflow to jobs for individuals that turn 57.5 and are no longer required to actively search for a job. In contrast to Heyma and van Ours (2005), our dataset follows individuals both before and after the policy change. Making use not only of variation in age, but also variation over time, we are able to estimate treatment effects for various groups of treated individuals. Moreover, instead of focussing only on unemployment to employment transitions, we also shed light on substitution between various social insurance programs by considering both DI receipt and early retirement as competing risks for the exit out of unemployment. Indeed, one of the desired consequences of imposing stricter requirements for receiving UI benefits is to save on government spending by decreasing the number of individuals eligible for receipt of these benefits. This can be done directly by excluding individuals from receiving UI benefits in case they do not comply with the new rules, or by making the receipt of UI benefits so unattractive that individuals start to look for alternatives themselves. However, the alternative that the government has in mind (paid employment) might not be the most attractive alternative from the point of view of the individual. The unemployed worker might instead substitute towards other benefit types, such as disability benefits or, in case of the elderly, early retirement benefits (provided that eligibility conditions for such schemes can be met). Since costly substitution between programs that insure different risks should be avoided, spill-over effects among these government programs are an important part of policy evaluation. In this paper, we are able to furnish empirical evidence as to the importance of the various channels. Estimating flexible form competing risks duration models using difference-in-difference and regression discontinuity approaches, we find that for several groups of individuals that were affected by the policy change, the stricter search requirements did significantly increase the entry rate into employment by about 6 percentage points. However, we also find evidence of a higher outflow to disability insurance by 2.5 to 4 percentage points, a presumably unwanted side-effect of the policy change. In contrast, no significant substitution from UI benefits towards early retirement benefits could be found.

The remainder of the paper is set up as follows. Section 2 presents some important aspects of the Dutch UI system, with a focus on changes in the system aimed at the older unemployed. It also gives a brief description of the sickness/disability insurance (DI) benefit and early retirement systems and changes therein. Theoretical effects of an increase in search requirements are considered in section 3. The empirical analysis starts out in Section 4 with a description of the data and the selection of treatment and control groups for analysis. Section 5 presents the estimation strategy and some descriptive evidence, before continuing to estimation results given in Sections 6 and 7. Finally, Section 8 studies post-unemployment job characteristics. Section 9 concludes. 


\section{Institutional Context}

This section gives an overview of the UI benefit system in the Netherlands and reports important policy changes aimed at the elderly. It also considers changes in the DI and early retirement system that could possibly affect the inflow in these social insurance schemes for older unemployed workers. Our focus is on the years 2001-2005, as the data available to us are informative on this time period.

\subsection{The Dutch Unemployment Insurance System and Developments from 2001- 2005}

\subsubsection{The Dutch Unemployment Insurance System}

In the Netherlands, three types of UI benefits can be received: short-term UI-benefits, wage-related UIbenefits and follow-up-benefits. In order to be eligible for short-term UI-benefits, an individual needs to have worked at least 26 weeks out of the 39 weeks before becoming unemployed (the 26-out-of-39 requirement) and be 'available for work' (for example, an individual cannot live abroad or join an educational program). Short-term benefits can be received for at most 6 months and are set to $70 \%$ of the prevailing minimum wage or $70 \%$ of average last-earned wage, whichever one is less. Wage-related benefits are paid out when the claimant fulfills the 26-out-of-39 requirement and in addition worked for 52 days or more in at least 4 out of the 5 (calendar) years before he became unemployed. ${ }^{1}$ The benefits are set to $70 \%$ of the average wage earned at the last employer, with a maximum of about $€ 29,000$ a year in 2003 . Follow-up benefits are to be received after the maximum duration of wage-related benefits have expired, and have the same height as short-term benefits. An overview of the system is given in Table 1.

The maximum duration of wage-related benefits is a step-wise function of age. A potential employment history is calculated by adding the number of years from the year an individual turned 18 until five calendar years before unemployment starts to the 4 (or 5) years that an individual worked before becoming unemployed. A longer potential employment history implies a longer UI eligibility, with a maximum of 5 years for wage-related benefits. For most individuals, maximum duration for follow-up benefits is two years. However, if a worker loses his job at age 57.5 or above, follow-up benefits can be received for up to 3.5 years. A graphical representation of potential benefit durations for wage-related and follow-up UI benefits and their relation to age at unemployment is given in Figure 1.

\subsubsection{Developments in the Dutch Unemployment Insurance System 2001-2005}

In the period under study, a number of reforms in the UI system took place. Here we present an overview of reforms specifically aimed at (increasing the participation rate of) older unemployed.

\footnotetext{
${ }^{1}$ Years in which an individual takes care of a child who is less than 6 years old are also considered as a working year. For a child between 6 and 12 years of age, half a year per year of care is added to the number of working years.
} 
First, employers were obliged to pay part of the UI benefits if they fire an employee aged 57.5 or above from May 11th 2001 onwards. $^{2}$ Second, for individuals becoming unemployed on or after August 11th 2003, follow-up-benefits were abolished. Instead, those aged 50+ when becoming unemployed fell under the socalled IOAW scheme with payments that provide the household with an income of $70 \%$ of minimum wage after expiry of UI benefits. This is the same level of benefits previously provided for by follow-up UI benefits. The difference with receiving extended benefits is that in IOAW applying for jobs is compulsory and that benefits are tested against the income of the spouse. A third reform became effective on January 1st 2004 and changed the conditions for UI benefit receipt: older unemployed (57.5+) were no longer exempted from the requirement to actively search for jobs. Finally, starting from the 1st of January 2005, potential duration of wage-related benefits for new UI recipients were made (partly) dependent on actual employment history instead of merely on age. An employment history is calculated from the number of years actually worked between 1998 and the calendar year preceding unemployment and the number of years potentially worked before 1998 (1998-18- year of birth). An overview of the developments aimed at older unemployed can be found in Table 2.

Focus of the present paper is the January 1st 2004 reform when older $(57.5+)$ job seekers lost their special status in terms of search requirements. Post-reform, they were treated in the same way as all other unemployed, including an intake meeting and a meeting in which they are informed about the search obligation. ${ }^{3}$ Search requirements stipulate to apply to at least 4 jobs in 4 weeks. Noncompliers run the risk of being severely sanctioned: benefits can be reduced with a maximum of 20 percentage points for 16 consecutive weeks. In case of recidivism, this can be as high as 30 percentage points. Table 3 shows that in the year 2004, in which the policy change became effective, there was an increase of about 5 percentage points in the share of sanctions due to noncompliance with the search requirement as a percentage of the total number of sanctions. Since there was also about a 5 percentage point increase in the number of UI benefit recipients needing to report their search effort, these descriptives suggest that there were indeed also sanctions levied on older individuals. ${ }^{4}$ Table 4 shows that huge cuts in benefits indeed take place in practice: noncompliers are punished with an average 20 percentage points cut in benefits (from 70 to 50 percent of previous/minimum wage) for 14 consecutive weeks. ${ }^{5}$ Appendix A.1.1 gives a more detailed description of the Dutch Unemployment Insurance procedure.

\footnotetext{
${ }^{2}$ The contribution in benefit payments depends on the size of the firm, with a maximum of $30 \%$ of gross UI payments for companies with more than 50 employees. An extra restriction is that a maximum of $3 \%$ of total wages in the company may be paid as UI benefits to older ex-workers.

${ }^{3}$ On May 1st 1999, the obligation to attend an intake meeting and the requirement to accept 'suitable' jobs (if offered by the unemployment office) was extended to include the elderly who turned 57.5 on May 1st 1999 or later.

${ }^{4}$ Anecdotal evidence (Verveen et al., 2005) suggests that the elderly were more likely to comply with the newly imposed search requirements. Indeed, Table 3 only gives descriptive evidence of the actual imposition of sanctions on the elderly. In our data, we unfortunately do not observe when and whether sanctions have been imposed, nor do we observe the actual search effort of individuals.

${ }^{5}$ The shorter average duration is caused by the fact that there are some individuals who started working before the end of the sanction spell.
} 
Not only newly unemployed were affected by this change in search requirements. For elderly that were already unemployed, a transitional arrangement was in place: the search requirement was activated on January 1st 2004 for all individuals that have been unemployed for less than one year at December 31st 2003 and did not yet reach the age of 62 years and 2 months at the 1st of January 2004. Moreover, all individuals that did not reach the age of 57.5 before the 31st of December 2003 also needed to continue searching when turning 57.5, even if they have been unemployed for more than a year. Exceptions to the obligation to search were made, among others, for individuals aged 64 or above on their first day of unemployment, for individuals starting up their own business or taking part in an educational program which is considered necessary for re-integration, and for individuals aged 57.5 or above at the 31st of December 2003 who received DI benefits just before entering UI.

\subsection{The Dutch Disability Insurance System}

It is well known that not all individuals entering DI are actually disabled. Autor and Duggan (2003) find that DI is used as a substitute for UI in the U.S.. For the Netherlands, Koning and van Vuuren (2007) find that $3 \%$ of all dismissals takes place via the DI scheme. These findings suggest that individuals can to some extent choose to enter DI, and therefore a change in DI inflow may be triggered by adjustments in the UI system. However, instead of being 'pushed' from UI into DI (as is the case when search requirements for eligibility of UI increase) individuals can be 'pulled' into DI upon modification of the latter system. We therefore present an overview of the Dutch DI system. Nearly all policy changes from 2001-2005 were aimed at employers and are irrelevant to the unemployed. An overview of major adjustments is deferred to Appendix A.1.2.

The Dutch DI System in 2001 consists of two main Acts: the Sickness Act (SA) and the Disability Act (DA). The SA provides an income floor to anyone with or without employer, including those receiving UI benefits, in case of sickness or disability. In most cases, UI benefit recipients who become ill or otherwise disabled receive $70 \%$ of their former wage for up to 1 year. After receiving sickness benefits for a full year, an individual enters the Disability Act. After medical examination, a worker who is considered at least partially disabled $(>15 \%)$ is eligible for DA payments of up to $70 \%$ of last earned wage, depending on the degree of disability. Individuals aged 58 and older receive wage-related DA benefits for a maximum of 6 years, and individuals in the age range 53-57 for 3 years. From the age of 59 onwards, wage-related DA benefits can therefore be received until age 65, after which an individual becomes eligible for old age pension payments. After wage-related DA benefits have expired, individuals receive a follow-up benefit. The follow-up benefit is also dependent on age and previous wage and can be received for as long as the disability lasts.

\subsection{The Dutch Early Retirement System}

In the Netherlands the old age pension system consists of three tiers: the first tier encompasses social assistance in the form of a basic pension, financed by premiums levied on the working age population (a 
PAYG system), the second tier consists of supplementary schemes provided by employers and employees in industry-specific collective agreements (CAO's) and the third and last tier comprises private, individually financed pensions and savings.

The single largest change in the early retirement system in the late 1990's and early 2000's was the transformation of the second tier. Early retirement pension payments that used to be actuarially unfair and financed by a PAYG system were slowly replaced by actuarially fair capital funded schemes. Instead of applying a flat rate, which eliminated the financial incentive to continue working, pension payments in the new system decreased upon retirement at an earlier age. Moreover, the replacement rate was greatly reduced (from $80 \%$ to $70 \%$ when retiring at the age of 62 in some of the larger sectors). As from the 1st of April 1997, the pension system for civil servants (ABP) was the first to transfer to the new 'Pre-Pension' (PP) scheme. Euwals et al. (2010), examining this change in the early retirement system, find that the shift to an actuarially fair system with lower pension wealth induced individuals to retire later.

Individuals that are at least 40 years old at the time they become unemployed, continue to build up their second tier pension rights as long as they receive wage-related UI benefits. Moreover, for individuals who are at least 57.5 years of age when they become unemployed, this 'free' building up of pension rights continues until they reach the legal retirement age of 65 . However, since with the introduction of the new PP scheme a switch to a capital-funded system was enacted, early retirees were no longer building up their pension rights, making it even more attractive for UI benefit recipients to stay unemployed.

\section{Theoretical considerations}

In a standard two-state job search model, an increase in search requirements affects job search both directly and indirectly. The direct effect is to increase search effort for individuals that would otherwise search less than the newly defined threshold. However, introducing a required minimum of formal search also implies an increase in the cost of search for each job application. This (i) decreases search effort for individuals already conforming to the new search requirements by means of informal search, (ii) decreases the value of unemployment (which decreases the reservation wage) and thereby increases search effort, (iii) by decreasing the value of unemployment also decreases the value of the subsequent job and thereby decreases search effort (the so-called 'entitlement effect', Mortensen (1977)). Following van den Berg and van der Klaauw (2006), who argue that in case of older workers the use of informal channels is limited, we can expect the first indirect

effect to be modest. Moreover, for elderly the 'entitlement effect' effect is also small: a possible new spell of UI benefits can only comprise a limited number of years, since from the age of 65 they will receive pension payments instead. Search requirements may therefore be especially effective for the elderly.

On the worker demand side, the job offer probability for the older unemployed might change as a result of enforcing minimum job search requirements: formal search requirements could lead to fake applications by the elderly, thereby stigmatizing job applications of older workers such that employers will be less willing to hire 
them. More in general, an increase in the required amount of search effort could lead to a changing average productivity of applicants: assuming that initially only the most motivated individuals with good labor market prospects were engaged in active job search, average productivity of the applicant pool decreases, again leading to a lower job offer probability for older unemployed. In conclusion, it is not immediate that introducing formal job search as a conditioni for UI benefit receipt will increase the job finding rate of elderly.

Now consider a three-state search model in which the option to collect a type of benefit other than UI is introduced. Since formal search requirements reduce the value of receiving UI benefits, whereas the value of receiving other benefits stays constant, individuals can decide to forgo UI benefits and collect those other benefits instead (that is, if eligibility conditions can be met with positive probability). In case of older unemployed, two important other social insurance schemes are DI and early retirement pensions. Naturally, the subsitution to another type of benefit is more likely the higher the initial value of receiving these benefits. Considering the choice between substitution towards DI benefits or early retirement pension payments, the balance is more likely to tip in favor of DI benefits since the expected value of applying for DI benefits is high. First, the possible duration of DI benefits is 6 years for individuals aged 58 and older, which is longer than the maximum of 5 years of wage-related UI benefits. Furthermore, the total potential benefit duration (PBD) of UI benefit receipt is not decreased by an intervening spell of sickness/disability, already providing individuals with a rationale to substitute to DI (if only temporarily). A change in search requirements in UI could therefore just make the required difference for DI to be a worthwhile alternative. ${ }^{6}$ In contrast, early retirement pension payments have become less attractive over time. Since in the old pension system (VUT) retirement benefits were at a flat rate of around $80 \%$ from age 59 onwards (or 60, 61 depending on the sector of previous employment), there used to be a high incentive to switch to receipt of early retirement pensions at that pivotal age. Since with the new capital-funded PP scheme individuals' old age pension replacement rates continued to increase with retirement age until an age of 65 , the incentive to switch to early retirement was greatly reduced.

\section{Data and Selection of Treatment/Control Groups}

We make use of administrative data obtained from Statistics Netherlands. The so-called SSB (Social Statistical Files) data is obtained from municipalities, tax authorities and social insurance administrations. It contains detailed information on income variables and beginning- and enddate of benefit and wage payments for all individuals living in the Netherlands. Using this information, we can determine the labor force state of an individual for the years 1999-2005 with daily precision. The states that we can distinguish include fulltime and part-time employment, being unemployed (receiving unemployment insurance), being ill/disabled (receiving sickness or disability benefits) and entering (early) retirement (receiving pension payments).

\footnotetext{
${ }^{6}$ Note also that following an increase in compulsory search, the higher burden put on the elderly could cause an actual deterioration in health for some, thereby increasing the probability of receiving DI benefits directly and making substitution more likely.
} 
The information in the SSB is merged with information on education available from the unemployment office. Since the data on education is only available from 2001-2006, information on education is missing for the short-term unemployed that became unemployed in the years 1999 or 2000 and only have one spell of employment over the years 2001-2006. Since this group is likely to be selective we exclude individuals becoming unemployed before the year 2001.

In order to examine the policy change, we select groups of older individuals (55.5-59.5 at the time of inflow) becoming unemployed in 2001, 2003 and 2004. Individuals becoming unemployed before 2003 are unaffected by the policy change as long as they are older than 57.5 on the 1st of January 2004. Since only individuals with an age at inflow of 55.5 years or older are selected for analysis, our selected unemployment spells starting in 2001 are unaffected by the change in policy. They are therefore subject to the initial regulations: those that become unemployed and are younger than 57.5 at the time of inflow are required to search for a job. However, if they are still unemployed when they turn 57.5, they can quit searching without consequences for their UI eligibility. Individuals that are 57.5 years or older at the time of inflow never need to report any search activities. Our 2001 inflow can therefore serve as a control group.

Individuals entering the UI benefit system in the year 2004 are affected by the policy change, in various ways. Unemployed aged 57.5+ and entering unemployment in 2004 need to actively search for new employment, allowing us to study the effect of being required to search from the start of the unemployment spell versus never having a formal requirement to search. Those younger than 57.5 at time of inflow need to continue searching at the age of 57.5. Here we can examine the effect of needing to continue searching at age 57.5 versus being allowed to stop searching at that age.

The 2003 inflow is affected in a way that is different from the individuals that enter unemployment in 2004. The group of individuals aged 57.5 and over at the time they start their unemployment spell at first instance did not need to search for a job. However, when they were still unemployed at the 1st of January, they were required to start searching. In order to only estimate the effect of an increase in search requirements, we drop individuals that became unemployed from the 11th of August onwards. Our 2003 inflow sample therefore is not affected by a cancellation of extended benefits (see Section 2.1.2). Using the 2003 treatment group, we can investigate the effect of needing to search formally after being unemployed for 5-12 months, versus not being required to search at all.

To sum up, we select a control group (inflow in 2001), a 'partly' treated group (inflow in 2003) and a 'fully' treated group (inflow in 2004) for analysis. We drop less than $1 \%$ of these individuals because of unobserved covariates (mainly education). Moreover, since search requirements were abolished in 2004 for individuals that were in DI before flowing into the UI system, we select only individuals that came from private sector jobs to ensure that all individuals in our treatment groups were indeed affected by the reform. ${ }^{7}$ Table 5 shows us the distribution of states of origin for the various years of inflow. Inflow from DI benefits

\footnotetext{
${ }^{7}$ Another reason to exclude these individuals is that their latent probabilities to find a job or to enter another DI spell are very different from those of previously employed individuals.
} 
is slightly larger in 2001, following the declining trend in the number of DI recipients as a percentage of the labor force in the Netherlands (de Jong, 2008). We therefore find no evidence that our inflow sample confronts us with selectivity issues. The final sample comprises 30053 observations for analysis.

\section{$5 \quad$ Methodology and Descriptive Statistics}

\section{$5.1 \quad$ Regression Specifications}

We specify hazard models for the exit rate to a job, disability benefits and early retirement payments and adopt regression discontinuity and difference-in-difference approaches as our main identification strategies.

Let $\tau^{I}$ be the day of inflow, $a^{I}$ the age at inflow and $T$ total unemployment duration. Moreover, let $a_{\tau}$ denote a time-varying variable indicating the age of an individual at calendar time $\tau$. The transition rates from unemployment to some exit state $x$ are affected by a vector of observable characteristics $X$ at the time an individual starts his or her unemployment spell. We assume that exit to any state can be described by a proportional hazard model following a piecewise constant exponential function.

In a first regression specification, we select individuals becoming unemployed in 2001 (non-treated) and in 2004 (treated). Then the instantaneous probability of leaving unemployment to exit state $x$, given that the individual is still unemployed at unemployment duration $t$ is given by the hazard rate $\theta^{x}\left(t \mid X, \tau^{I}, a^{I}, a_{\tau}\right)$ :

$$
\theta^{x}=\lambda(t) \exp \left\{X^{\prime} \beta+\gamma_{1} I^{04}+\gamma_{2} I\left[a^{I} \geq 57.5\right]+\gamma_{3}\left(I^{04} * I\left[a^{I} \geq 57.5\right]\right)+\gamma_{4} I\left[a_{\tau} \geq 57.5\right]+\gamma_{5}\left(I^{04} * I\left[a_{\tau} \geq 57.5\right]\right)\right\}
$$

where $I^{04}$ is a dummy indicating whether the year of inflow was $2004\left(\tau^{I}=2004\right), I\left[a^{I} \geq 57.5\right]$ is an indicator function equal to 1 when an individual is at least 57.5 years of age at inflow into unemployment, and the interaction effect $I^{04} * I\left[a^{I} \geq 57.5\right]$ picks up a first treatment effect: the need to fulfill formal search requirements from the start of unemployment when an individual is at least 57.5 years old at inflow, i.e. an 'always search' effect. The indicator $I\left[a_{\tau} \geq 57.5\right]$ is a time-varying variable equal to 1 from the time an individual turns 57.5 and the interaction $I^{04} * I\left[a_{\tau} \geq 57.5\right]$ picks up a second treatment effect: the need to formally continue search when a person turns 57.5 as opposed to being allowed to stop searching at that moment, i.e. a 'continue search' effect.

Note that the inclusion of the parameters $\gamma_{4}$ and $\gamma_{5}$ do not only allow us to examine a second treatment effect, but is also needed to correctly estimate the first treatment effect: since we are using individuals aged 55.5-57.5 as our control group to identify the 'always search' effect $\gamma_{3}$ (the effect on the 57.5-59.5 year olds) we do need to correct for the fact that the younger individuals that became unemployed in 2004 also got treated as from the age of 57.5 onwards.

A second regression takes only individuals aged 57.5-59.5, becoming unemployed either in 2003 (treatment group) or in 2001 (control group) to estimate the effect of the policy change for those that did not formally 
search for a job until being unemployed for 5-12 months:

$$
\theta^{x}=\lambda(t) \exp \left\{X^{\prime} \beta+\delta_{1} I^{03}+\delta_{2} I[\tau \geq 1 \text { Jan 2004] }]+\delta_{3}\left(I^{03} * I[\tau \geq 1 \text { Jan 2004] })\right\}\right.
$$

where $I^{03}$ indicates possibility of treatment if still unemployed at January 1st 2004 (i.e. inflow in 2003), $I[\tau \geq 1$ Jan 2004] is an indicator function equal to 1 from the moment an individual reaches the 1st of January 2004, and the interaction effect $I^{03} * I[\tau \geq 1$ Jan 2004] picks up a third treatment effect: the need to start fulfilling formal search requirements after 5-12 months in unemployment, for individuals aged 57.5-59.5 at the start of their unemployment spell, i.e. a 'start search' effect.

The baseline hazard $\lambda(t)$ for both empirical models specifies duration dependence in the form of a flexible piecewise constant function:

$$
\lambda(t)=\exp \left(\sum_{k=1}^{K} \mu_{k} I_{k}(t)\right)
$$

with $I_{k}(t)$ is an indicator function taking the value 1 if duration $t$ is in interval $k$. We specify $K=7$ duration intervals, defined as durations from 0-1 month, 1-2 months, 2-3 months, 3-6 months, 6-12 months, 12-24 months and 24+ months. We normalize $\mu_{1}=0$.

For both regressions, the density of total unemployment duration $T$ for a spell with exit state $x$ can therefore be written as:

$$
f_{i}^{x}(T \mid X)=\theta_{i}^{x}(T \mid X) \exp \left(-\int_{0}^{T} \theta_{i}^{x}(s \mid X) d s\right)
$$

The loglikelihood adds the contributions of uncensored and censored spells:

$$
L^{x}=\sum_{i \in\{n c\}} \log \theta_{i}^{x}(T \mid X)+\sum_{i}-\int_{0}^{T} \theta_{i}^{x}(s \mid X) d s
$$

where $\{n c\}$ denotes the set of noncensored spells: all individuals that are observed to exit to state $x$. A spell is considered censored when still ongoing at the 31th December 2004 or when an individual is observed to exit to a state other than $x$. Tables 7 and 8 in Appendix A.3 give a schematic overview of the identification of the parameters for both regression specifications.

In order to control for observed heterogeneity between the treatment and control groups, we include as background characteristics dummies for marital status, age and its square, nationality (Dutch, foreignborn with a western nationality, or foreign-born with a non-western nationality), and a dummy indicating whether there are any dependent children in the household. We furthermore control for education level in four categories: whether the highest diploma an individual received was primary school, a low level of highschool/the lowest level of higher education, a high level of highschool/a middle level of higher education or higher professional education/university. We also include a regressor on whether the individual is on a spell with a 'revived' UI right. A right is considered revived when an unemployment spell is interrupted by 
a job or sickness/disability spell and an individual gets back in unemployment (before having the chance to build up new UI rights). In this case, UI benefits can be received for the remainder of the potential benefit duration and therefore the total potential benefit duration for the individual is shortened. Two other indicators for potential benefit duration give information on whether an individual is on a spell with a long potential benefit duration (i.e. receives wage-related or extended benefits) or on short-term UI-benefits (a potential benefit duration of 6 months). Moreover, we include the quarters of the year as time-varying variables, thereby allowing for seasonal effects on outflow. In regression (1) instead of imposing a quadratic age-effect, we include a number of time-varying age-regressors (turning 56, turning 57, turning 58 etc.) and interactions of these age-regressors with the year of inflow in UI. In this way we try to account for the discontinuous shift in retirement behaviour during the period 2001-2005, following changes in the pension system described in Section 2.3.

In regression (1) we need to take into account that the cancellation of extended benefits on the 11th August 2003 can affect the estimation of the parameter $\gamma_{3}$ : if this policy change caused a discontinuous shift in outflow (e.g. to a job) for 57.5-59.5 year olds as opposed to 55.5-57.5 year olds, the point estimate will be biased. Indeed, Tuit and van Ours $\left(2010^{a}\right)$ find that the inflow in UI benefits used to show a pronounced spike around the age of 57.5, which became more moderate after January 2004. Comparing characteristics of the inflow before and after January 2004, they conclude that high wage workers before the policy change were more likely to postpone unemployment until reaching the age of 57.5. In this case, our 2001 57.5-59.5 year olds have better characteristics than our 2004 inflow such that our 'always search effect' $\gamma_{3}$ estimates a lower bound of the effect of a search requirement change on outflow to jobs. Tuit and van Ours $\left(2010^{b}\right)$ also show that the number of married individuals that postpone unemployment until the age of 57.5 is relatively large. This can be explained by the fact that after UI benefits expire, all individuals aged $50+$ at the beginning of unemployment could continue their unemployment spell in a scheme called the IOAW in which the height of the benefits is exactly the same as the extended UI benefits (i.e. $70 \%$ of minimum wage) but the receipt of these benefits is conditional on income of the partner (see also Section 2.1.2). Indeed, plotting the inflow in UI as a function of age (following Tuit and van Ours, 2010 ${ }^{q}$ ) but showing it separately for married and single individuals, Figure 2a depicts that the spike in around age 57.5 in the years before 2004 was mainly driven by married individuals. ${ }^{8}$ In other words, individuals that have a partner who receives income have a higher incentive to postpone unemployment and receive UI benefits until age 65 . Discontinuation of the extended benefits on the 11th August 2003 therefore made married individuals aged 57.5 at the start of their unemployment spell disproportionally worse off. To capture this effect, we include an interaction effect of our treatment parameter $\gamma_{3}$ with being married. ${ }^{9}$

\footnotetext{
${ }^{8}$ In order to keep our figure comparable to that of Tuit and van Ours $\left(2010^{a}\right)$ we show inflow in UI for males only.

${ }^{9}$ Inclusion of this regressor generally does not affect our results. Note that this does not imply that the cancellation of extended benefits was ineffective: married individuals entering unemployment when being close to 60 , would turn 65 before exhausting their (3.5 instead of 2 years lasting) extended benefits and were only moderately affected. In contrast, married individuals younger than 57.5 at inflow lost a full 2 years of extended benefits. The fact that we find a zero result of the
} 


\subsection{Identification and Descriptive Evidence}

In order to give some insight into similarity and dissimilarity of the various treatment and control groups, background characteristics are given in Table 9. Note that for an unbiased estimate of the 'always search' effect $\gamma_{3}$, we need to assume that there is no change in some relevant characteristic for individuals becoming unemployed in 2001 versus those becoming unemployed in 2004, that is discontinuous at an age of 57.5 at inflow. For the 'continue search' effect $\gamma_{5}$ we need a similarly weak condition: in absence of the change in search requirements, there should not be a discontinuous change in the hazard rate into jobs (and other destination states) when turning 57.5 between individuals starting unemployment in 2001 versus individuals starting unemployment in $2004 .{ }^{10}$ For the start search effect $\delta_{3}$, the treatment effect is correctly identified under the assumption that individuals aged 57.5+ and starting unemployment in 2001 are a good control for the business cycle in the sense that they pick up any 'being in 2004 or beyond' effect that the inclusion of time-varying seasonal effects cannot control for.

Since the 'always search' effect can be considered a sort of before-after regression discontinuity design (RDD) we do not require our treatment and control groups to develop in the same way in order to correctly identify this effect. However, it is comforting to see that they do. Looking at individuals aged 57.5-59.5 in Table 9, we see that individuals becoming unemployed in 2004 seem to be more likely to have a child present in the household ${ }^{11}$ and tend to be slightly higher educated as compared to the unemployed in 2001 . To the extent that the increase in education for the inflow in 2004 is both typical for the 57.5-59.5 age group and discontinuous in age, our always search parameter $\gamma_{3}$ could be overestimating the true treatment effect on the outflow to jobs (assuming individuals with a higher education are to find jobs faster). However, since the increase in education seems to be a general phenomenon for the whole sample (aged 55.5-59.5), this effect will be picked up by the indicator for inflow in 2004. The same holds true for the fraction of individuals with a dependent child. Table 9 therefore gives no indication of a possible bias of the 'always search' effect $\gamma_{3}$.

Even though observable characteristics of treatment and control groups seem to develop in the same way, it is instructive to consider the possibility of a discontinuity in unobservables. One cause for such a discontinuity that we correct for in our regression could be the cancellation of extended benefits on August 11th 2003, as is discussed in the previous Section. Alternatively, anticipation of the policy change can also result in selective inflow into unemployment around the time the policy was initiated. Depicting the residuals of a regression of month dummies on inflow into the UI system between the years 2000 and 2005, Figure $2 \mathrm{~b}$ does not show any increase in discrepancy between the 57.5- and 57.5+ inflow around the 1st

\footnotetext{
cancellation of extended benefits is therefore inherent in our choice of treatment and control groups.

${ }^{10}$ Do note that there could be a general age effect, in that outflow from unemployment (into jobs) already decreases before turning 57.5. To the extent that this age effect is constant throughout the years, the age regressors are a sufficient control and our estimate of $\gamma 5$ is unbiased. Moreover, including an interaction of age and year of inflow does not change the results for outflow to jobs or DI benefits for any of the measured treatment effects.

${ }^{11}$ This probably indicates a cohort effect since the fraction of the younger age group in 2001 having a dependent child is similar to the fraction for the older age group in 2004 .
} 
of January 2004. The intuition for this is straightforward: since none of the individuals flowing into UI in 2003 were exempted from the new rules, there was no incentive to try to circumvent the policy change by speeding up the firing procedure. Anticipation therefore might only play a role in regression (2), in the sense that if individuals decide to start searching for a job before the 1st of January 2004, thereby flowing out of unemployment before 2004, the start search effect $\delta_{3}$ will be underestimated. However, it seems unlikely that an unemployed would increase search effort in December as a means to avoid the requirement to increase search effort in January.

Table 10 describes the proportion of individuals that end their unemployment spell with exit to a job, retirement and DI benefits respectively. Since the number of censored individuals is higher for individuals becoming unemployed in more recent years, the proportion as a fraction of individuals that are non-censored is given in parentheses. As expected, older individuals more often flow into retirement, at the expense of the outflow to jobs and DI benefits. Moreover, it appears that individuals becoming unemployed in 2004 flow into jobs more often than individuals becoming unemployed in 2001. More importantly, for exit to DI benefits the difference between the age groups seems to decline in the later years From this, we could conclude that there is at least some effect of the 2004 policy change: stricter search requirements decrease the relative gap in outflow to DI benefits between the 55.5-57.5 and 57.5-59.5 year olds. ${ }^{12}$ Since the increase in outflow to jobs over the years is a development that seems to impact all individuals, Table 10 provides no indication of an effect of tighter search requirements on the outflow to jobs. However, the average duration until a job is found is decreasing stronger over the years for the older age group than for the younger age group, from Table 11. This suggests a higher speed of outflow to jobs for older unemployed in recent years. Note, however, that the observation window for individuals first observed in 2004 is considerably smaller than for those that became unemployed in 2001. The average and median duration for the outflow to jobs for those starting their unemployment spell in 2004 are therefore considerably underestimated. Indeed, there is a $48 \%$ censoring rate for those aged 57.5-59.5 and becoming unemployed in 2004 (Table 10). We will therefore apply duration analysis in order to get a more detailed view of the effects of the policy change.

\section{Estimation Results}

\subsection{Nonparametric Results}

Since the decriptive statistics do not take censoring into account, it is instructive to estimate survivor and hazard functions for the various times of inflow and age groups. From Figure 3, depicting the nonparametric estimation of the (kernel) smoothed hazards, we can see that for exit to a job the difference in outflow

\footnotetext{
${ }^{12}$ From Table 10 it seems that instead of observing an increase in inflow to DI for the older age group, there is a decline in inflow to DI for the younger age group. Indeed, inflow in DI declined following changes in the DI system in 2002 (De Jong, 2008). The fact that there was no decline in DI inflow for individuals aged 57.5-59.5 indicates that there was another change specifically affecting DI inflow for this age group - for example, the change in search requirements.
} 
rate between the age groups is smaller for the 2003 and 2004 inflows as compared to the 2001 (and 2002) inflows. This is as expected, since for the 2001 inflow, the 57.5-59.5 year olds never needed to search for a job, whereas the 55.5-57.5 year olds did. This gives some confidence in a positive effect of the tightening of search requirements for the age 57.5-59.5 inflow $^{13}$. However, individuals that were slightly younger and entered unemployment in 2004 were also affected by the policy change: they needed to continue searching even when they turned 57.5. In order to separate these two effects, we resort to parametric duration analysis and estimate equation (1) specified in Section 5.1. Similarly, in order to separate a general business cycle effect (of becoming unemployed in 2003) from the effect of the policy change, we continue by estimating equation (2) parametrically.

\subsection{Parametric results}

Regression equation (1) is specified for the three exit states out of unemployment: exit to a job, (early) retirement, or DI benefits. The focus is on the coefficients $\gamma 3$ and $\gamma 5$, capturing the 'always search' and the 'continue search' effects. An overview of treatment effects for the two regression specifications is given in Tables 12 and 13. Full results from our basline model are given in Tables 14 and 15 (regression 1) and 16 and 17 (regression 2). Note that results are given in exponentiated coefficients and can therefore be interpreted as a change in the (overall) hazard ratio as a result of a 1-unit change in the corresponding covariate. If there is any positive effect of stricter search requirements for older unemployed on the inflow to jobs/early retirement/DI, we would therefore expect coefficients to be significantly larger than 1 . Separate models are estimated for males and females, following the results of Wald tests which for each exit state clearly rejected a joint model $(\mathrm{p}<0.01)$. A joint model is estimated on regression equation $(2)$ for exit to DI, since a Wald test indicated that joint estimation is acceptable $(\mathrm{p}=0.11)$. In our baseline model, which includes background regressors as described in Section 5.1, we indeed find 'always search' hazard ratios for the exit to jobs equal to 1.75 (males) and 1.96 (females). Loosely speaking, an unemployed man who is older than 57.5 at inflow and needs to search for jobs has a speed of outflow to jobs that is 1.75 times the speed of outflow of $57.5+$ year olds that do not face any search requirements. The effect of a search requirement becoming effective at age 57.5 when an individual is between 55.5 and 57.5 at the time of inflow (i.e. the 'continue search' effect) is of similar magnitude, increasing the hazard rate by a factor 1.95 (males) and 1.77 (females) over the remaining duration of the spell. Do note that the magnitude of the coefficients is not informative on the magnitude of the absolute differences in outflow rates: since the effect of continued search is measured only over the latter part of the unemployment spell, where outflow rates are lower for all individuals, the absolute effect of the search requirement change could very well be larger for the $57.5+$ year olds. We therefore graphically show in Figures 4, 5 and 6 the treatment effects by estimating parametric hazards for the treatment and control groups after estimation. The hazard functions are calculated for all treated individuals and subsequently

\footnotetext{
${ }^{13}$ Note from Figure 3 that also for exit to DI benefits, nonparametric hazard rates for the two age groups seem to move (much) closer together in later years.
} 
averaged in order to show an average (intention to) treatment effect on the treated. From a comparison of the parametric hazards for exit to a job and exit to DI, it can be seen that although point estimates for the treatment parameters for exit to DI are higher in terms of hazard ratios, the absolute effect on the hazard rate is smaller following a smaller baseline hazard for the exit to DI.

Since in a competing risk setting, an increase in the hazard rate cannot directly be interpreted as an increase in the number of individuals leaving to a certain exit state, we simulate in Figure 7 the treatment effects in terms of an increased outflow to jobs and disability benefits respectively. From this, we conclude that the outflow to jobs is expected to increase with about 6 percentage points following an introduction of compulsory search requirements both for individuals aged 57.5+ that needed to search from the start of their unemployment spell ('always search') and for an individual aged 57 that needed to continue search when turning 57.5 ('continue search'14). However, there was also an increase of 2.5 to 4 percentage points in take up of disability benefits for individuals aged 57.5+ and aged 57 respectively. An unwanted side-effect of stricter search requirements therefore is an increase in the proportion of individuals that stop claiming UI benefits, but requesting other social insurance payments instead. For our 'start search' effect measured by the parameter $\delta_{3}$ in equation (2), we can see from Figure 7 that there is an insignificant increase in outflow to jobs and a small and insignificatn increase in outflow to DI benefits for an individual that is already unemployed for 9 months and only then is requested to show his job search efforts to the unemployment office. As for the exit to retirement, there is no general pattern in the estimated treatment effects in Tables 12 and 13. As explained in Sections 2.3 and 3, the transition from a PAYG to an actuarially fair capital funded early retirement system greatly reduced the incentive to retire early in the early 2000's. Since this effect cannot be separated from the effect of search requirements in UI, our estimates are biased downwards. Cumulative incidence functions for this exit state are therefore omitted. ${ }^{15}$

\section{Sensitivity Analysis}

After estimation of the model including only the treatment effects (column 1 of Tables 12 and 13), our baseline model including background regressors (column 2), adding as regressors the sector of the previous job (column 3) and incorporating gamma distributed unobserved heterogeneity parameters (column 4), a few concerns on the interpretation of the coefficients remain. Results on selected sensitivity checks are reported in Tables 18 and 19. In all sensitivity checks, we compare our results to that of the baseline model in column 2 of Tables 12 and 13.

\footnotetext{
${ }^{14}$ Since the initiation of the treatment effect is perfectly dependent on the age at entry, we choose to depict the cumulative incidence function for our 'continue search' effect for an individual aged 57 at entry. In this case, the treatment becomes effective after 6 months in unemployment.

${ }^{15}$ In estimating the treatment effect in terms of outflow probabilities, we do need to take retirement into account as an alternative exit state. Indeed, if outflow to retirement decreased, it means more individuals can exit to a job and therefore the estimated treatment effect (in terms of outflow probabilities) for exit to jobs will be underestimated if exit to retirement is not taken into account.
} 
First, the age range from 55.5-59.5 might be too wide to be able to precisely estimate the 'always search' and 'continue search' parameters in regression (1). We therefore estimate equation (1) using only 56.5-58.5 year-olds. As can be seen from column 2 of Table 18, treatment parameters for exits to jobs, early retirement or disability hardly change.

Second, for regression equation (2), instead of only selecting individuals that became unemployed in 2003 until the 11th August we can choose to form a treatment group containing all individuals becoming unemployed in 2003. The treatment parameters remain of similar magnitude, again strengthening our confidence that the cancellation of extended UI benefits does not interfere with our results.

Third, we can make use of a different control group. In column 3 of Table 18 and Table 19 we show results when using the individuals becoming unemployed in 2002 instead of 2001 as a control group. Interestingly, in regression (1) the estimated treatment effects for exit to disability seem slightly larger for males, and slightly smaller for females using this control group. Moreover, the 'start search' effect for exit to a job as estimated in regression (2) becomes significantly positive for females.

A large number of other sensitivity checks were carried out ${ }^{16}$ : we included average (monthly) wage earned in the previous occupation as an indicator of productivity. Unfortunately, including previous wage as a regressor results in a loss of about $70 \%$ of observations. Including this regressor did not lead to large changes in results, either qualitatively or quantitatively. The coefficient estimate on wage itself was often close to 1 and never significant.

Another concern with regression (1) might be that it is important to account for the possibility that business cycle effects influence older age groups differently (Jaimovich and Siu, 2009). However, including an interaction effect of age with year of inflow did not lead to large changes in the estimates. Moreover, adding also an interaction of age with our treatment group $\left(\gamma_{2}\right.$ - being older than 57.5 at entry into unemployment $\left.{ }^{17}\right)$ and an interaction of age with our 'always search' treatment parameter $\gamma_{3}$ (i.e. with age as our control function specified in a totally flexible way) leads to larger coefficient estimates on our treatment effects. In order to keep the specification parsimonious, we exclude these extra regressors from our baseline specification.

Analogous to the flexible age-function, we can specify a flexible 'marriage-function' by interacting our dummy for being married with the indicator for the year of inflow in unemployment $\left(\gamma_{1}\right)$, and with the indicator for being a member of the treatment group $\left(\gamma_{2}\right)$. This again did not lead to large changes in the estimated treatment effects.

In order to strengthen our believe that the regression specifications do not erroneously return significant results on treatment parameters, we re-ran both regression specifications using 50.5-54.5 year olds, letting our 50.5-52.5 olds play a fake control group (fake in the sense that they were also treated) and indeed we

\footnotetext{
${ }^{16}$ Results are available from the authors on request.

${ }^{17}$ Since the MPH specification dictates individuals with a higher baseline hazard to have a higher (absolute) treatment effect, an interaction of age with the dummy for treatment group can take into account possible differential effects of treatment by age that do not need to follow the direction of the actual effect of age on outflow.
} 
could not find an extra effect of the policy reform for the (redefined) older age group. ${ }^{18}$ Another check on the effectiveness of the reform was to re-run our regression specification (1) using instead of individuals becoming unemployed in 2004 and 2001 as our treatment and control group, individuals becoming unemployed in 2001 and 1999 respectively (both groups of individuals were not treated). Indeed, we did not find any effect of this fake reform on outflow to jobs, early retirement, or disability benefits.

As a check on heterogeneity of treatment effects (over and above the heterogeneity dictated by the proportional hazard structure) we ran regressions on specific subgroups of the population. From a policy perspective, it is interesting to know whether search requirements are especially (and maybe only) effective for high employability individuals. These individuals face better prospects when actively searching for jobs and might therefore be affected the most by a compulsory search requirement. On the other hand, the same individuals could also be the ones that use informal search channels even without a search requirement, precisely because the expected payoff of searching is higher. Moreover, these are the same individuals who can be expected to have a lower disutility of working. We tested these hypotheses by running separate regressions by educational level. We could not derive any general pattern from the results of these regressions.

A general concern with the estimation of competing risks in a one-by-one equation setting is that time to exit for the different states might be interrelated. Although neglecting possible correlation in hazard rates to the various exit states should not influence the estimation of interaction/treatment effects as much as level effects, it is nevertheless instructive to jointly estimate the 3-equation model. For this aim, we specify a multivariate mixed proportional hazards model with Heckman-Singer (1984) heterogeneity. We make use 2 mass points of the heterogeneity distribution per equation and construct logit functions to estimate the mixing probabilities. A more elaborate description of the Likelihood is given in Appendix A.2. Results of the estimation are given in Table 20. Sign and magnitude of the estimates are very similar to the single equation estimation results.

As a final sensitivity check, note that the 'continue search' effect $\gamma 5$ should be close to the effect measured by Heyma and van Ours (2005) who study the same policy but only make use of variation at the agethreshold to study exit rates to jobs. Selecting a sample of individuals aged 55.5-57.5 they study the effect of the discontinuity in search requirements at the age of 57.5 before the policy change. In our regression specification (1) we can check for possible misspecification. Take for example a misspecification of the way duration dependence enters the model(s): in our model, we need that the possible bias in the specification of duration dependence is the same for individuals becoming unemployed in 2001 and in 2004 (absent any level effects). In the model by Heyma and van Ours (2005) it is needed that there is no bias in the specification for duration dependence. Similar results therefore strenghtens confidence in the functional form specifications. Second and related, the assumption that absent any discontinuity in policy design at the age-threshold, there would be a continuous age effect on the outflow to a job can be checked by comparing our results to results from a simple RDD estimation as done in Heyma and van Ours (2005). Indeed, our estimated 'continue to

\footnotetext{
${ }^{18}$ For exit to a job for males, we did find a significant and positive estimate of 1.43 on our 'always search' $\gamma 3$ parameter.
} 
search' effect is close to being the reciprocal of their 'discontinue to search' effect which is to be expected if both models are correctly specified. Moreover, from the full results of our baseline model depicted in Tables 14 and 15 we can see that before policy change, there was a discontinuity at age 57.5 both for males for females. After the policy change, this discontinuity disappeared. ${ }^{19}$

\section{Post-unemployment job characteristics}

Because an expansion of search requirements entails an increase in search costs, thereby decreasing the value of being unemployed, it is predicted that the 1st of January 2004 policy change does not only increase search effort, but also decreases the reservation wage. Both have an upward effect on the outflow to jobs. Although an increase in search effort is the effect that policy makers would like to establish enforcing these search requirements, another possibility is that elderly are matched to lower-skilled and lower-paid jobs. It is therefore interesting to examine the effects on post-unemployment job characteristics more closely. Table 21 gives a first indication of the importance of these effects. For most of our groups, the wage distribution after unemployment is not first-order stochastically dominated by the wage distribution before unemployment. Instead, the wage distribution after unemployment is more dispersed than the distribution before unemployment, indicating that although some individuals need to give up some salary in order to get re-employed, there is also a considerable group of individuals that receives a higher wage after the unemployment spell. If anything, the difference between wages previously earned and wages accepted is decreasing over time between the age groups. Whereas the decrease in accepted wages and previous wages for unemployed aged 57.5-59.5 is large when they become unemployed in 2001, individuals aged 55.5-57.5 are earning wages comparable to their previous wage. For individuals becoming unemployed in 2003 and 2004 however, the loss (or gain) in wages accepted is very much equal between the two age groups. In conclusion, these descriptives do not provide direct evidence for a declining reservation wage theory.

Not only reservation wages may decline upon an increase in search costs, individuals may also start searching for jobs that are different in other respects. For example elderly may only be able to find part-time employment after an unemployment spell. Table 22 describes the fraction of individuals that were in parttime, full-time or flexible work arrangements both before and after the unemployment spell. As is intuitive, older individuals (aged 57.5+) indeed more often take up part-time employment after a spell of unemployment, trying to bridge the last couple of years to the pensionable age of 65 (i.e. they take up so-called 'bridge-jobs'). Although the fraction of full-time workers has decreased over the years, there does not seem to be a clear pattern between the treatment and control groups: individuals becoming unemployed in any year are about half as likely to have a full-time job after their unemployment spell. In contrast, employment with flexible hours has become more popular as an option to take up a job for older unemployed. Taken

\footnotetext{
${ }^{19}$ This can be seen from the parameter estimates presented in Tables 14 and $15: \gamma_{4} * \gamma_{5}=0.59 * 1.84 \approx 1$ for males and $\gamma_{4} * \gamma_{5}=0.57 * 1.89 \approx 1$ for females.
} 
together, Table 22 does not indicate that the 2004 policy change had large effects on post-unemployment job characteristics.

\section{Conclusions}

As the challenges associated with an ageing population become more prominent and many countries increase statutory retirement age, it becomes all the more important to document the effects of labor market policies on behaviour of the elderly. This paper deals with one such policy, namely the imposition of job search requirements for older unemployed. Using a large administrative database covering all wage and social security payments to Dutch individuals in the years 1999-2005, we can examine the effect of a tightening of search requirements which was specifically aimed at the elderly. The reform, coming into effect on the 1st of January 2004, made an end to the special treatment of unemployed elderly. Before the law was initiated, an individual turning 57.5 did not need to report his/her search effort to the unemployment office any longer. The new policy however required elderly to continue actively searching for a job even after turning 57.5. Using difference-in-difference techniques and regression discontinuity designs within a duration framework, we estimate the effect of this reform on outflow to jobs, early retirement and disability benefits for the various affected groups of individuals aged 55.5 to 59.5. The main conclusions pertain that although outflow to jobs increased with 6 percentage points in the 24 months after a tightening of search obligations, this was accompanied by a 2.5 to 4 percentage point increase in the number of individuals that used DI benefits as an alternative exit route. In light of the evidence that UI benefits and DI benefits are alternative pathways to early retirement, one would expect outflow to retirement to increase as well. However, our estimation methods cannot separate between the changes in the UI and in the early retirement system, and therefore cannot provide evidence for an increased outflow to early retirement. An interesting venue for further research would be to estimate the impact of extended search conditions for elderly on their after-unemployment job characteristics. Theory predicts that an increase in search costs will decrease reservation wages and might therefore lock the elderly into low-skilled and low-paid jobs, another unwanted side-effect of a policy that is meant to induce elderly to become more active labor market participants.

\section{References}

Abbring, J.H., van den Berg, G.J. and J.C. van Ours (2005), The effect of unemployment insurance sanctions on the transition rate from unemployment to employment, The Economic Journal (115) 602-630

Autor, D.H. and M. Duggan (2003) The rise in the disability rolls and the decline in unemployment, Quarterly Journal of Economics (118), 157-205

Caliendo, M., Tatsiramos, K., and A. Uhlendorff (2009) An analysis of unemployment duration and employment stability based on a regression-discontinuity approach, Working Paper, Bonn 
Card, D. and P.B. Levine (2000), Extended benefits and the duration of UI spells: evidence from the New Jersey extended benefit program, Journal of Public Economics (78) 107-138

Carling, K., Holmlund, B. and A. Vejsiu (2001), Do benefit cuts boost job findings? Swedish evidence from the 1990's, The Economic Journal (111:474) 766-90

Chan, S. and A.H. Stevens (2001), Job loss and employment patterns of older workers, Journal of Labor Economics (19:2) 484-521

De Graaf-Zijl, M. and P. Hop (2007), 45-plus en 55-plus in de SUWI-keten. Hoe vergaat het de oudere werkloze op zoek naar werk? Working Paper, SEO (nr. 2007-92)

De Jong, P. (2008), Recent changes in Dutch disability policy, APE report

Euwals, R., van Vuuren, D., and R. Wolthoff (2010) Early retirement behaviour in the Netherlands: evidence from a policy reform, De Economist, (158) 209-236

Heckman, J. J. and B. Singer (1984) Econometric duration analysis, Journal of Econometrics (24) 63-132

Heyma, A. and J. van Ours (2005) How eligibility criteria and entitlement characteristics of unemployment benefits affect job finding rates of elderly workers, unpublished manuscript

Jaimovich, N. and H.E. Siu (2009), The young, the old, and the restless: demographics and business cycle volatility, American Economic Review (99:3) 804-826

Koning, P. and D. van Vuuren (2007), Hidden Unemployment in Disability Insurance, Labour (21:4), 611-636

Kyyrä, T., and V. Ollikainen (2008), To search or not to search? The effects of UI benefit extension for the older unemployed. Journal of Public Economics (92) 2048-2070

Lalive, R. (2008), How do extended benefits affect unemployment duration? A regression discontinuity approach, Journal of Econometrics, (142:2) 785-806

Lalive, R., Van Ours, J. and J. Zweimüller (2006), How changes in financial incentives affect the duration of unemployment, Review of Economic Studies, (73:4), 1009-1038

Manning, A. (2009), You can't always get what you want: The impact of the UK Jobseeker's Allowance, Labour Economics (16), 239-250

Mortensen, D.T. (1977), Unemployment insurance and job search outcomes, Industrial and Labor Relations Review (30) 595-612

Petrongolo, B. (2009), The long-term effects of job search requirements: Evidence from the UK JSA reform, Journal of Public Economics (93) 1234-1253

Røed, K. and T. Zhang (2003), Does unemployment compensation affect unemployment duration?, The Economic Journal, (113;484) 190-206

Tuit, S. and J.C. van Ours $\left(2010^{a}\right)$, How changes in unemployment benefit duration affect the inflow into unemployment, Economics Letters, (109) 105-107

Tuit, S. and J.C. van Ours $\left(2010^{b}\right)$, How changes in unemployment benefit duration affect the inflow into unemployment, Center Discussion Paper 
Van den Berg, G.J., van der Klaauw, B. and J.C. van Ours (2004), Punitive sanctions and the transition rate from welfare to work, Journal of Labor Economics (22) 211-241

Van den Berg, G.J. and B. van der Klaauw (2006), Counseling and monitoring of unemployed workers: theory and evidence from a controlled social experiment, International Economic Review (47) 895-936

Van Ours, J. and M. Vodopivec (2006), Does Reducing Unemployment Insurance Generosity Reduce Job Match Quality? Journal of Public Economics (92) 684-695

Verveen, E., Zuidam, M. and M. Engelen (2005), Quick scan sollicitatieplicht ouderen, Research voor Beleid (on behalf of the Council for Work and Income) 


\section{Appendices}

\section{A.1 Institutional Background}

\section{A.1.1 The Dutch Unemployment Insurance Procedure}

An unemployed job seeker is expected to register at the unemployment office (UWV werkbedrijf) on the first day following unemployment. During this first intake, the unemployment office makes an estimation considering the employability of the individual. On the basis of objective characteristics such as profession, labor market experience, education and age, and the impression by the caseworker during the intake itself (subjective characteristics) the individual is distributed to a certain 'phase'. Phase 1 individuals are assumed to be able to find work within 6 months without any further assistance. Other individuals (phases 2,3 and 4) receive job search assistance and can be assigned to ALMP's by the unemployment office.

Within a maximum of 8 days following the intake the individual again needs to report at the unemployment office. During this meeting, the unemployed is informed about his rights and duties. Specifically, he is informed about the procedures regarding the job search requirements. An individual needs to make a minimum of 4 applications per 4 weeks to 'suitable' jobs. In the first six months of unemployment, a job is considered suitable when (i) the individual has obtained exactly the level of education required for the job $^{20}$ (ii) earnings are not below or not 'significantly below' earnings in the previous job (iii) travel time per day is not more than 2 hours. Apart from the 4-applications-in-4-weeks-requirement an individual is also expected to consult a public vacancy information system. Moreover, he needs to accept any suitable jobs offered to him by the unemployment office. Apart from these job search and job acceptance requirements, an individual is expected to participate in the advised active labor market programs (if any).

In the weeks following this second intake, an individual needs to report to the caseworker at the unemployment office every 4 to 6 weeks. These meetings are meant primarily for checking if job search requirements are being lived up to. In case the caseworker suspects that an individual did not make enough job applications, an official at the unemployment office is informed. The official then decides whether a sanction needs to be imposed, of which the individual is notified (in written form). The unemployed is then given the opportunity to defend his case (either written or spoken). ${ }^{21}$ If it is decided that the individual was to blame for the lack of job applications, he is send a letter in which it is explained when and with what amount his benefits are cut. The maximum cut for a first misbehavior corresponds to a decrease in benefits by 20 percentage points for 16 consecutive weeks (i.e. from $70 \%$ to $50 \%$ of previous wage/minimum wage). This cut is the same regardless of the individual receiving short-term, wage-related, or follow-up benefits. In case the individual was only to blame partially, the cut is 10 percentage points. In case the individual did not follow up on the

\footnotetext{
${ }^{20}$ Individuals with a master degree are also obliged to accept work on the bachelor level

${ }^{21}$ It can also occur that the official, by checking the formal evidence on job applications, is the one to discover that the individual does not comply to the job search requirements. In this case, he contacts the caseworker to confirm his suspicion or he contacts the unemployed individual immediately.
} 
job search requirements a second time within two years, the benefit cut can be as a high as 30 percentage points.

\section{A.1.2 Changes in the DI System 2001-2005}

For completeness, in this section we present changes in the DI system that were mainly aimed at employers. The presumably largest changes in the DI system took place in 2002 and 2004. From April 1st 2002, the Gatekeeper Improvement Act (Wet Verbetering Poortwachter) specifies that both employers and employees must prove that they have put enough effort in preventing inflow in the DA during the one year period of sickness spend in the SA. When the unemployment office decides that the reintegration programme does not suffice, the period in which the employer pays sickness benefits (the SA period) is extended for at most one year. Alternatively, DA payments to the employee are refused or reduced. Incentives to enter the DA are therefore significantly decreased. However, in absence of an employer, the Act is not expected to have reduced SA inflow from unemployed workers.

Since January 1st 2002, employers get a $2 \%$ reduction on the DA premium paid for a worker at least 57 years of age (on the 1st of January of that year). An employer might therefore be more willing to hire $57+$ year olds. Since employers' DA premiums comprised $4.76 \%$ of gross wage, this implies that less than $0.1 \%$ of gross wage could be saved by hiring a 57+-year old. Note again that this policy provides incentives for employers, and is not likely to influence behaviour of the unemployed. Although the number of job offers to older unemployed might have increased slightly as a result of this reform, the savings on hiring a 57+-year old are so small that this is not likely to influence our results. Another possibly relevant adjustment came into effect on the 1st of July 2003. As from this date, it is possible for employers to accept responsibility for payment of SA benefits to former employees (becoming unemployed less than 1 month before they get sick). ${ }^{22}$ In exchange, employers' SA premiums are reduced. This change could reduce inflow in SA of UIbenefit recipients in the first month of unemployment. However, only 26 mainly small employers took up this new right until January 1st 2005. The policy change was therefore considered unsuccessful and was abolished in May 2006. It is therefore unlikely that this temporary adjustment in the system will affect our results. Another reform, institutionalized on the 1st of January 2004, portayed an extension of the maximum length of SA benefits from 1 to 2 years. For the employer, this meant that an ill employee would cost him/her a maximum of two years of wage payments, instead of one. From this moment on, also unemployed individuals received two years of SA benefits before transferring to the DA. As with the Gatekeeper Improvement Act, such a policy measure aimed at increasing reintegration incentives of employers does not have a bite for individuals without an employer. Another law that we consider was governed on the 1st of January 2004 and dictated that employers do not have to pay basic (non-differentiated) DA premium when hiring a 50+ year old. Because this affects all individuals in our sample (aged 55.5-59.5) equally, this new policy cannot influence our results. Finally, on the 1st August 2004, the collective agreement on DA for self-employed is

\footnotetext{
${ }^{22}$ The act is known as the Act Personal Liability SA (Wet eigen risico dragen Ziektewet, WEZ).
} 
abolished. From that date on, self-employed are expected to self-insure via private insurers. Since we do not consider self-employed in our analysis, the change does not affect our estimates.

\section{A.2 Multivariate Mixed Proportional Hazard Model with Heckman Singer het- erogeneity}

The hazard rate for exit state $x$ is defined as:

$$
\begin{aligned}
& \theta_{1}^{x}(t \mid X)=\lambda(t) \exp \left\{X^{\prime} \beta\right\} v_{1}^{x} \\
& \theta_{2}^{x}(t \mid X)=\lambda(t) \exp \left\{X^{\prime} \beta\right\} v_{2}^{x}
\end{aligned}
$$

Where the constants are normalized to zero for identification.

The baseline hazard $\lambda(t)$ specifies duration dependence in the form of a flexible piecewise constant function:

$$
\lambda(t)=\exp \left(\sum_{k=1}^{K} \mu_{k} I_{k}(t)\right)
$$

With $I_{k}(t)$ the indicator function taking the value 1 if $t$ is in interval $k$. There are $K=7$ duration intervals, defined as durations from 0-1 month, 1-2 months, 2-3 months, 3-6 months, 6-12 months, 12-24 months and $24+$ months. We normalize $\mu_{1}=0$.

Assuming an exponential distribution, the survivor function for surviving from period $t_{0}$ up to period $t_{1}$ for a spell with exit state $x$ can be written as:

$$
\begin{aligned}
& S_{1}^{x}\left(t_{1} \mid X, t_{0}\right)=\exp \left(-\int_{t_{0}}^{t_{1}} \theta_{1}^{x}(s \mid X) d s\right)=\frac{\exp \left(-\exp \left\{X^{\prime} \beta\right\} t_{1} v_{1}^{x}\right)}{\exp \left(-\exp \left\{X^{\prime} \beta\right\} t_{0} v_{1}^{x}\right)} \\
& S_{2}^{x}\left(t_{1} \mid X, t_{0}\right)=\exp \left(-\int_{t_{0}}^{t_{1}} \theta_{2}^{x}(s \mid X) d s\right)=\frac{\exp \left(-\exp \left\{X^{\prime} \beta\right\} t_{1} v_{2}^{x}\right)}{\exp \left(-\exp \left\{X^{\prime} \beta\right\} t_{0} v_{2}^{x}\right)}
\end{aligned}
$$

The likelihood contribution for 1 individual reads

$$
L_{i}=p_{1} \prod_{x=1}^{X} \theta_{1}^{x}(t \mid X)^{d^{x}} S_{1}^{x}(T \mid X)+p_{2} \prod_{x=1}^{X} \theta_{2}^{x}(t \mid X)^{d^{x}} S_{2}^{x}(T \mid X)
$$

With $d^{x}$ an indicator function equal to 1 if exit to state $x$ is observed and $X$ the number of exit states ( 3 in our case). The parameters $p_{1}$ and $p_{2}$ are probabilities assigned to the mass points, specified as logit functions:

$$
p_{1}=\frac{1}{1+\exp \left(q_{1}\right)}, p_{2}=\frac{\exp \left(q_{1}\right)}{1+\exp \left(q_{1}\right)}=1-p_{1}
$$

The (log)likelihood is maximized w.r.t. $X^{\prime} \beta, \mu_{k}, v_{i}^{x}$ and $q_{1}$. By assuming only partial mixing, the number of parameters in the probability functions that need to be estimated has been reduced from 7 to 1 . 


\section{A.3 Figures and Tables}

Figure 1. POTENTIAL UI BENEFIT DURATION

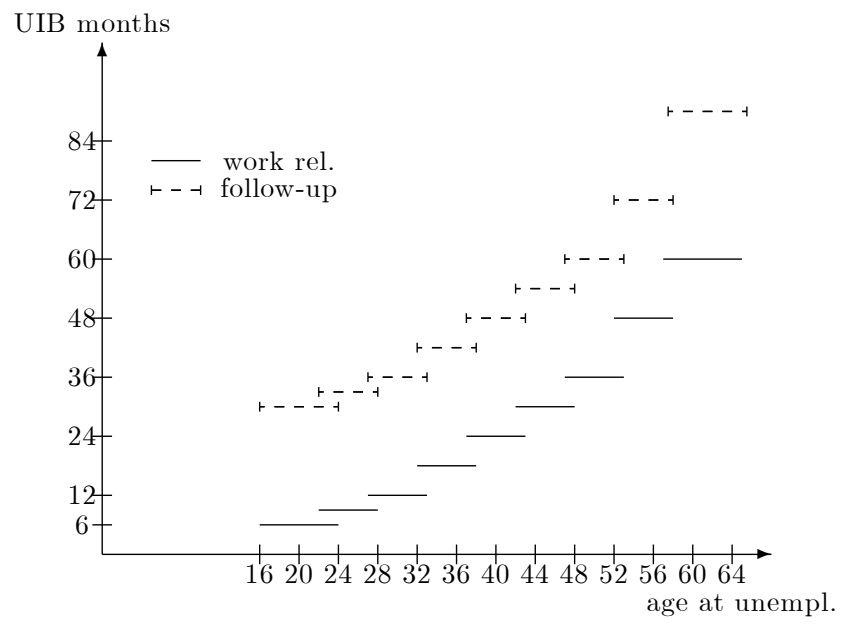

Figure 2a: INFLOW IN UI 2001-2005

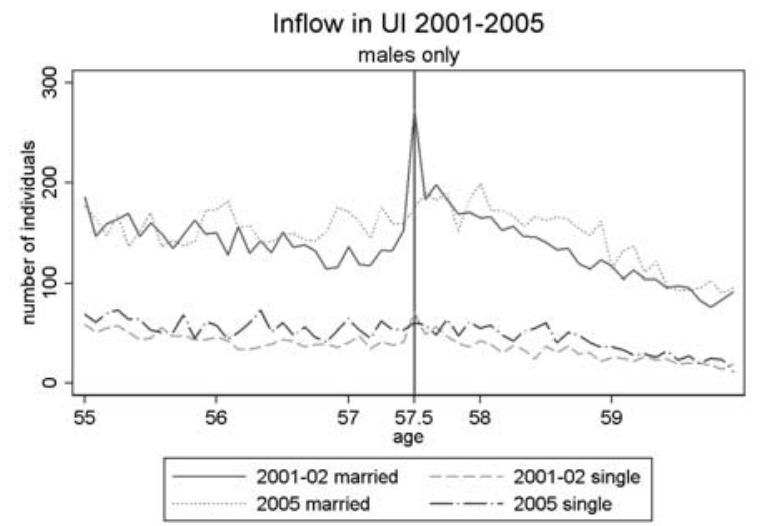

Figure 2b: INFLOW IN UI 1999-2005

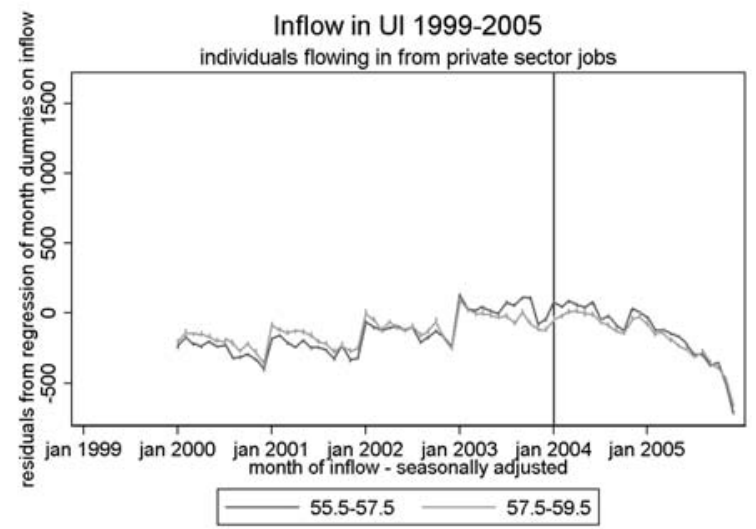


Figure 3: NONPARAMETRIC ESTIMATION OF HAZARD FUNCTIONS
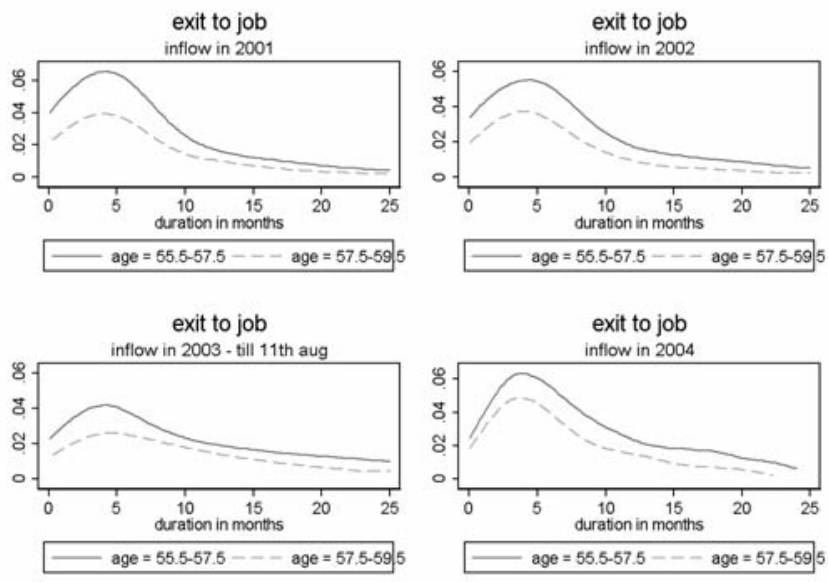

exit to a job
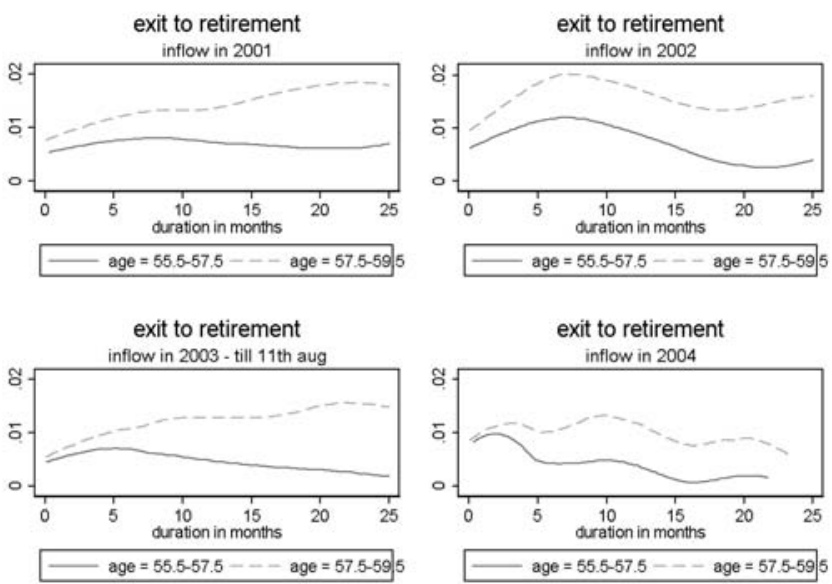

exit to retirement
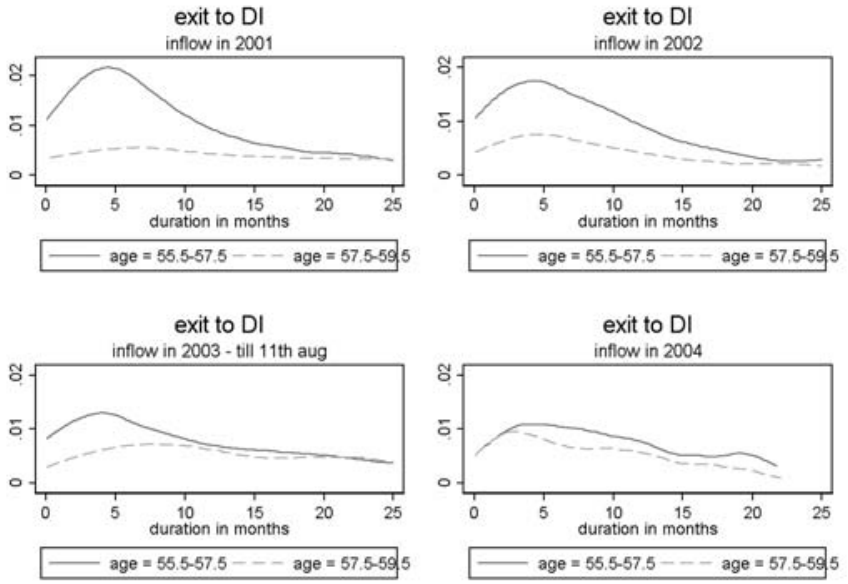

exit to disability 
Figure 4: PARAMETRIC ESTIMATION OF HAZARD FUNCTIONS

Exit to Job for Males

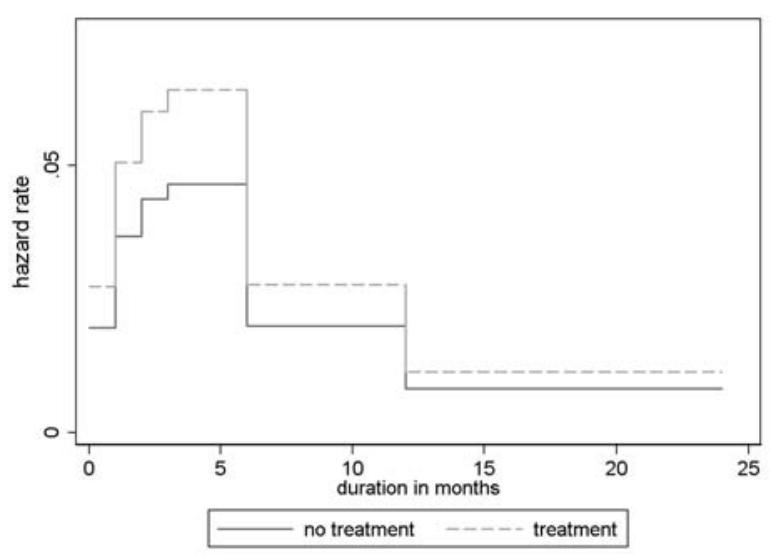

always search

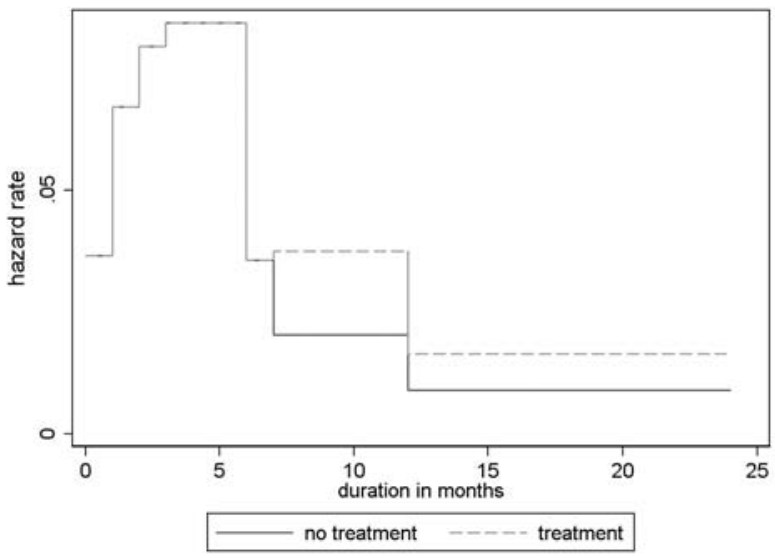

continue search

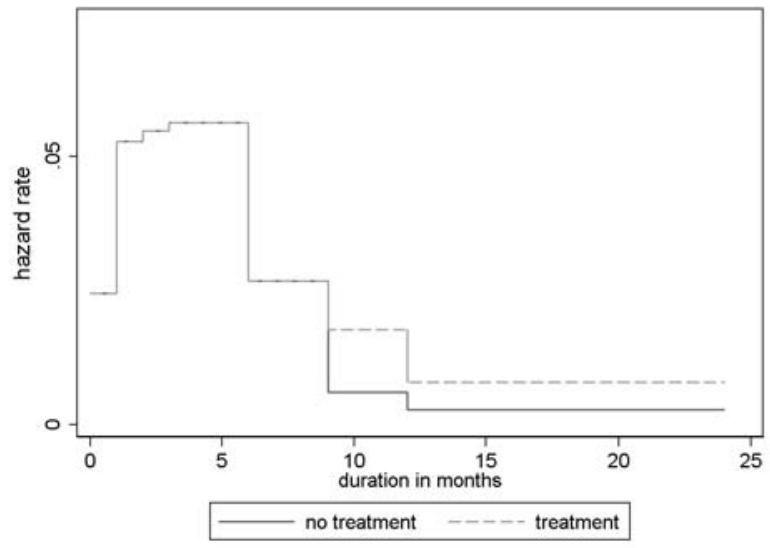

start search 
Figure 5: PARAMETRIC ESTIMATION OF HAZARD FUNCTIONS

Exit to Retirement for Males

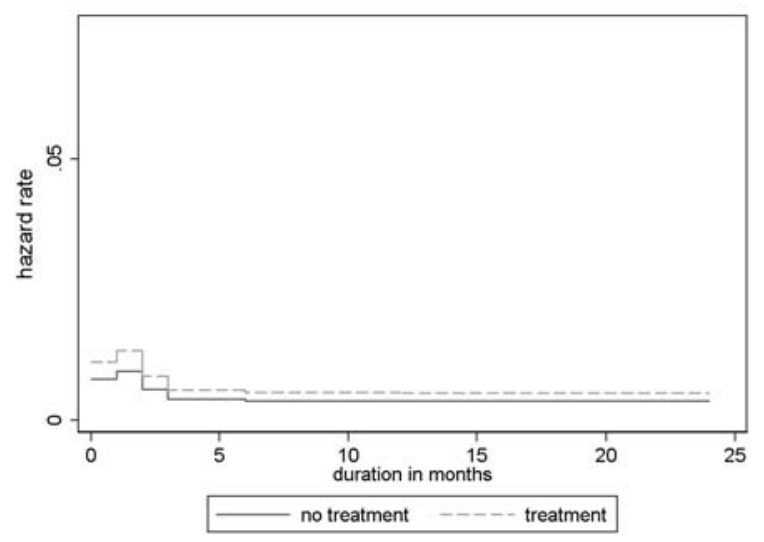

always search

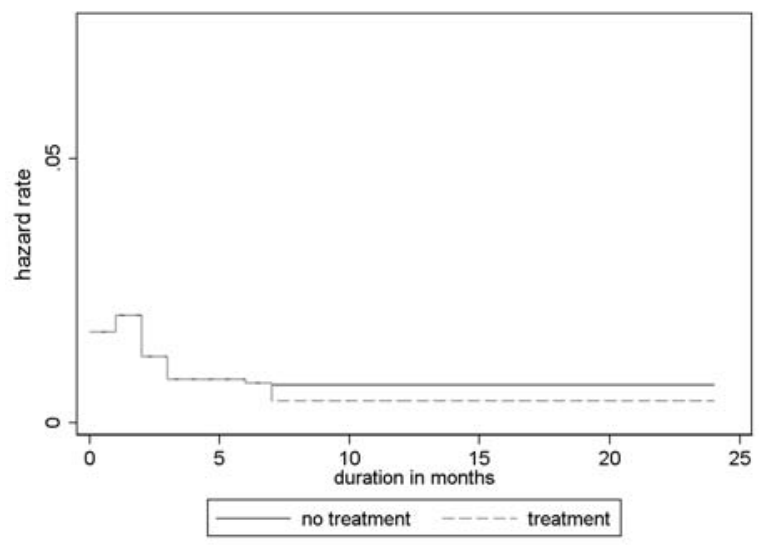

continue search

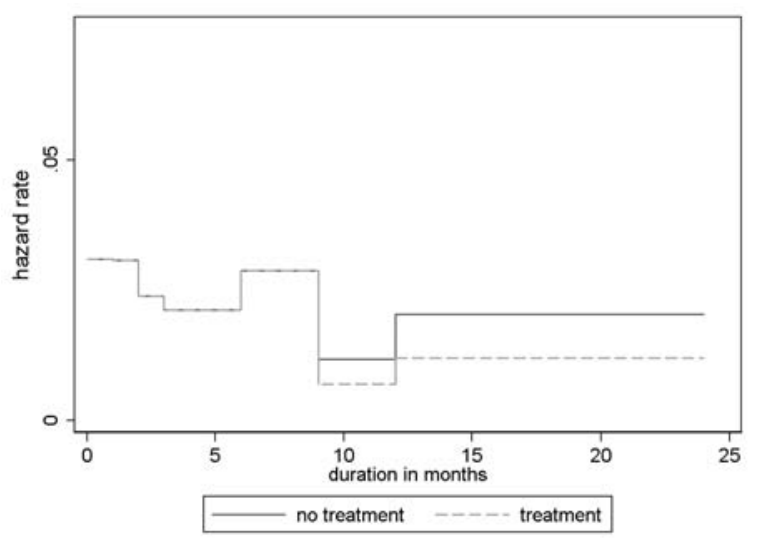

start search 
Figure 6: PARAMETRIC ESTIMATION OF HAZARD FUNCTIONS

Exit to Sickness/Disability for Males

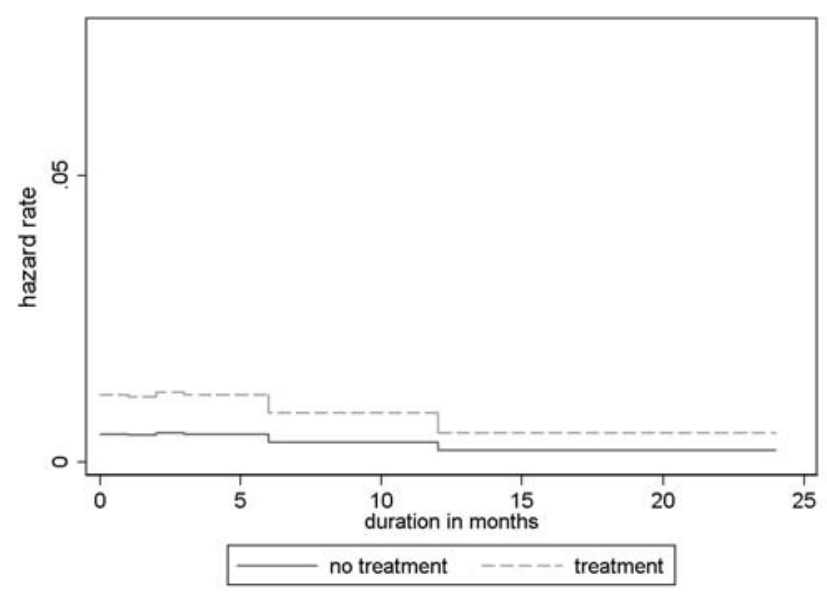

always search

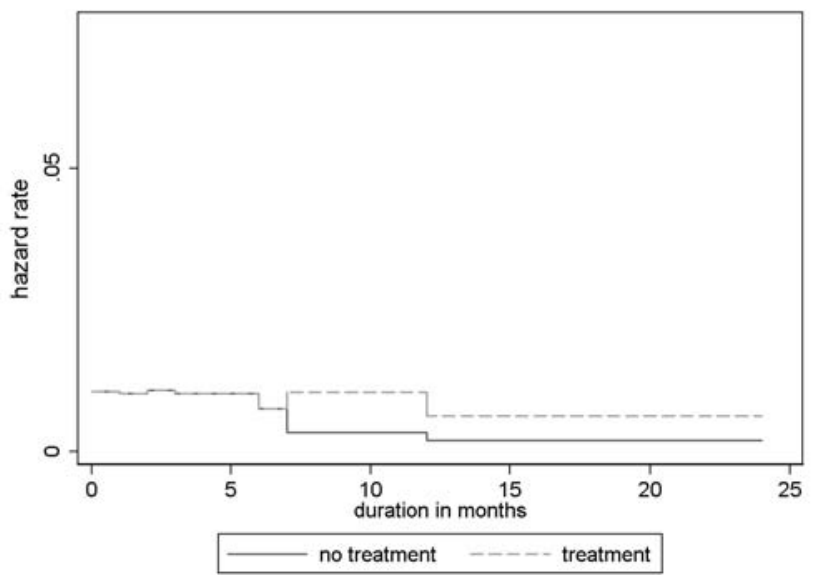

continue search

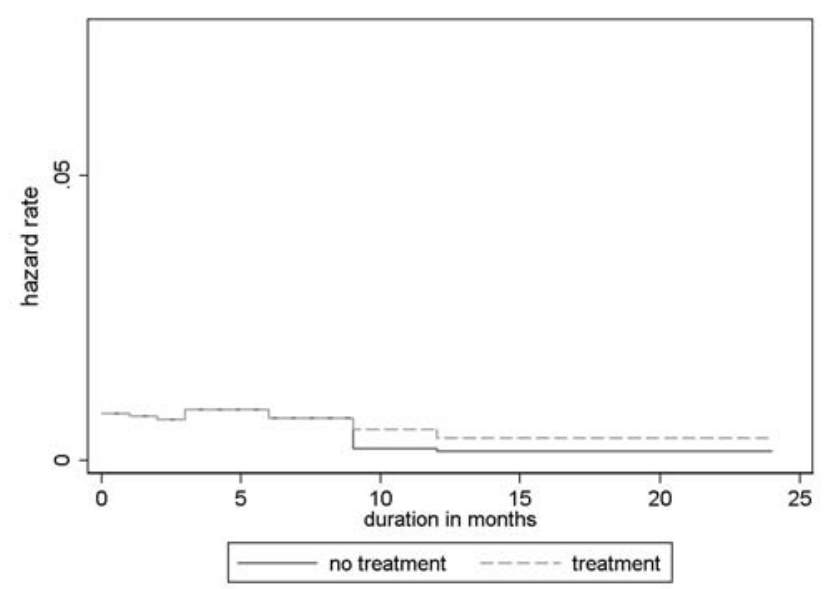

start search 
Figure 7 - CUMULATIVE INCIDENCE FUNCTIONS

Exit to job for Males

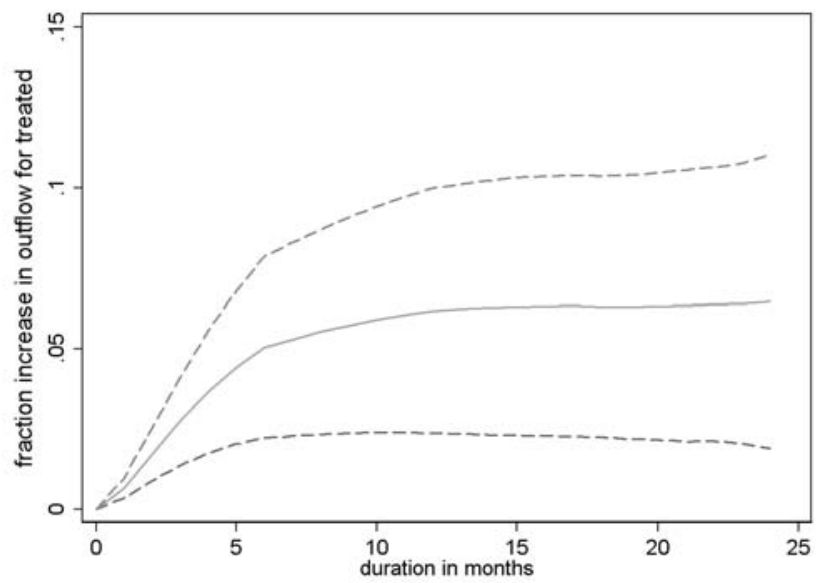

always search

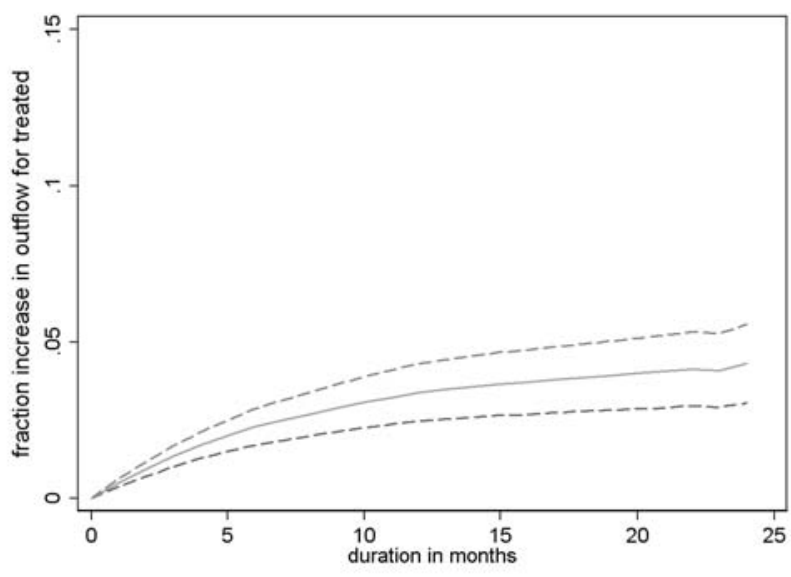

continue search

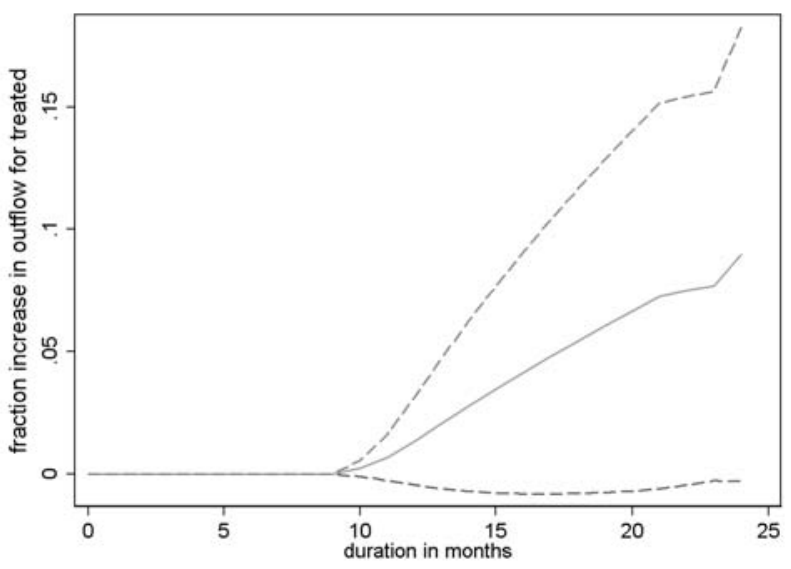

start search
Exit to Sickness/Disability for Males

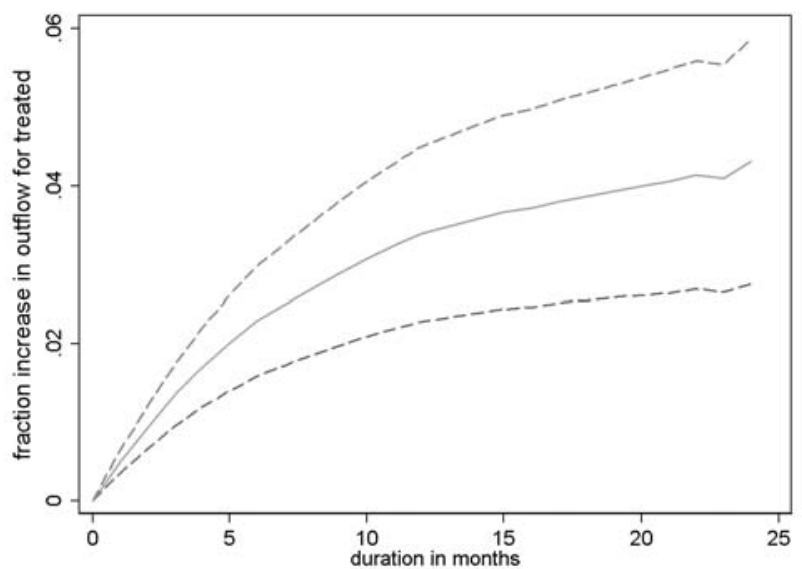

always search

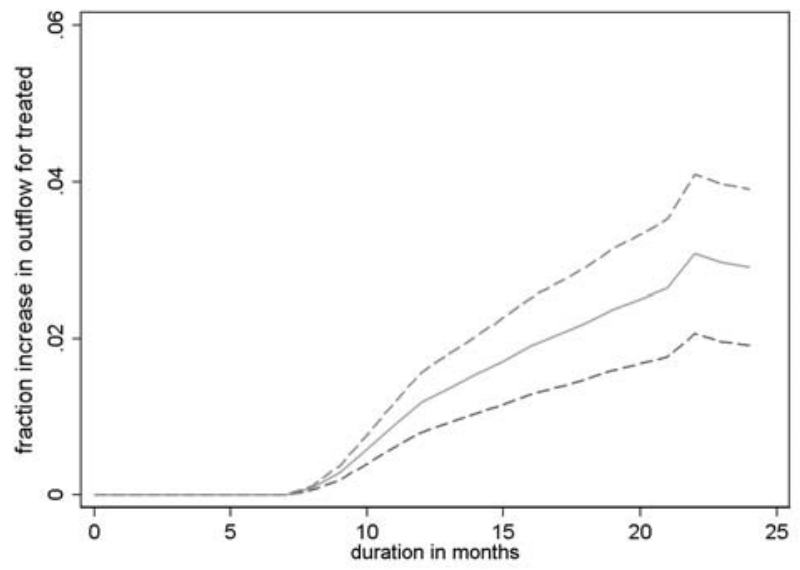

continue search

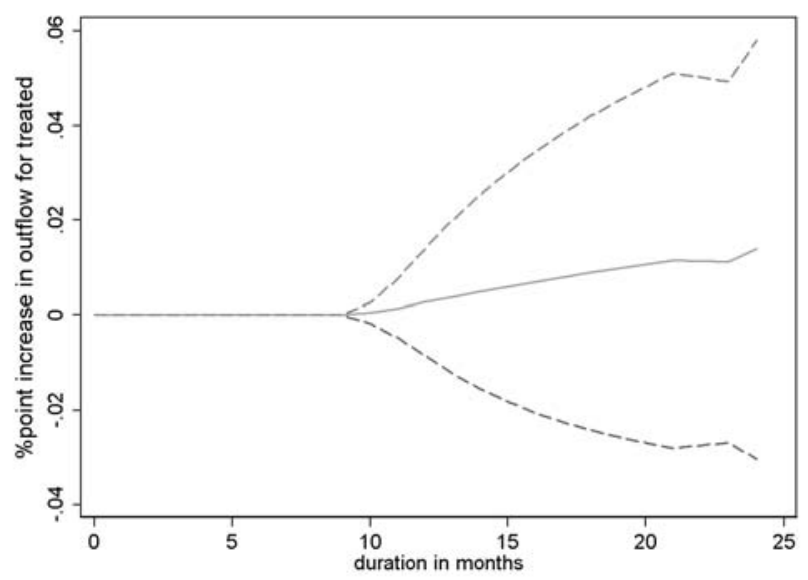

start search 
Table 1. ELIGIBILTY REQUIREMENTS, DURATION AND HEIGHT OF UI BENEFITS 2001-2005

\begin{tabular}{|c|c|c|c|}
\hline type of UI benefit & eligibility requirements & duration & payment \\
\hline short-term UI-benefits & 26-out-of-39 weeks requirement & 6 months & $\begin{array}{l}70 \% \text { of minimum wage or } \\
70 \% \text { of previous wage } \\
\text { whichever is lower }\end{array}$ \\
\hline wage-related UI-benefits & $\begin{array}{l}26 \text {-out-of-39 weeks requirement } \\
+4 \text {-out-of- } 5 \text { years requirement }\end{array}$ & $\begin{array}{l}6 \text { months to } 5 \text { years, } \\
\text { dependent on age }\end{array}$ & $70 \%$ of previous wage \\
\hline follow-up-benefits & $\begin{array}{l}26 \text {-out-of- } 39 \text { weeks requirement } \\
+4 \text {-out-of- } 5 \text { years requirement }\end{array}$ & $\begin{array}{l}2 \text { years if }<57.5 \text { at time } \\
\text { of unemployment, } \\
\text { otherwise } 3.5 \text { years }\end{array}$ & $\begin{array}{l}70 \% \text { of minimum wage or } \\
70 \% \text { of previous wage } \\
\text { whichever is lower }\end{array}$ \\
\hline
\end{tabular}

Note: benefits are granted to a maximum (about 29.000 euro per year in 2003)

Table 2. OVERVIEW OF CHANGES IN THE UI-SYSTEM AIMED AT THE ELDERLY, 2001-2005

\begin{tabular}{|l|l|}
\hline \hline date & policy change \\
\hline 2001, may 11th & employers pay part of UI-benefits for $57.5+$ year olds \\
\hline 2003, aug 11th & follow-up-benefits cancelled \\
\hline $\mathbf{2 0 0 4}$, jan 1st & $\mathbf{5 7 . 5}+$ year olds are (also) required to search actively \\
\hline 2005, jan 1st & max. UI duration determined partly by employment history \\
\hline 2006, oct 1st & $\begin{array}{l}\text { max. UI duration reduced from } 60 \text { to } 38 \text { months } \\
\text { payments increased from } 70 \% \text { to } 75 \% \text { in first two months } \\
\text { 26-out-of-39 becomes } 26 \text {-out-of-36 }\end{array}$ \\
\hline \hline
\end{tabular}

Table 3. NUMBER OF SANCTIONED INDIVIDUALS PER YEAR

\begin{tabular}{lrrrrr}
\hline & 2002 & 2003 & 2004 & 2005 & 2006 \\
\hline \hline total & 28774 & 34829 & 49368 & 48440 & 38931 \\
- as a \% of number of individuals in UI & 7.68 & 7.35 & 9.04 & 9.15 & a) \\
non-compliance with required \# of job applications & 12999 & 15120 & 23808 & 22327 & 15729 \\
- as a \% of number of individuals in UI & 3.47 & 3.19 & 4.36 & 4.22 & a) \\
- as a \% of total number of sanctioned individuals & $\mathbf{4 5 . 1 8}$ & $\mathbf{4 3 . 4 1}$ & $\mathbf{4 8 . 2 3}$ & $\mathbf{4 6 . 0 9}$ & $\mathbf{4 0 . 4 0}$ \\
non-compliance with job applications on a suitable 'level'' & 65 & 76 & 93 & 113 & 78 \\
- as a \% of number of individuals in UI & 0.02 & 0.02 & 0.02 & 0.02 & a) \\
- as a \% of total number of sanctioned individuals & 0.23 & 0.22 & 0.19 & 0.23 & 0.20 \\
\hline \hline
\end{tabular}

Data on sanctions are aggregate statistics from the unemployment office (UWV).

a) could not be calculated since the number of individuals is calculated making use of our 1999-2005 data.

Publicly available aggregate statistics are on the number of benefits, not individuals. Since one individual

can receive multiple UI benefits within a year (and even at the same time) this figure cannot be used here 
Table 4. AVERAGE HEIGHT AND DURATION OF SANCTIONS

average height of sanctions - percentage points cut in UI benefits

\begin{tabular}{lrrrrr}
\hline & 2002 & 2003 & 2004 & 2005 & 2006 \\
\hline \hline total & 17.81 & 17.54 & 16.98 & 16.27 & 15.62 \\
non-compliance with required \# of job applications & 20.96 & 20.99 & 20.88 & 20.92 & 20.85 \\
non-compliance with job applications on a suitable 'level' & 23.06 & 22.24 & 23.98 & 24.69 & 22.37 \\
& & & & & \\
average duration of sanctions (in weeks) & & & & \\
\hline & 2002 & 2003 & 2004 & 2005 & 2006 \\
\hline \hline total & 7.49 & 7.42 & 7.93 & 7.48 & 6.93 \\
non-compliance with required \# of job applications & 14.77 & 14.07 & 14.07 & 14.23 & 13.83 \\
non-compliance with job applications on a suitable 'level' & 13.55 & 15.26 & 12.99 & 12.54 & 16.33 \\
\hline \hline
\end{tabular}

Data on sanctions are aggregate statistics from the unemployment office (UWV).

Table 5. ORIGIN OF UI SPELL (I.E. STATE OF INFLOW)

\begin{tabular}{|c|c|c|c|c|c|c|}
\hline year of inflow in UI & 2001 & & 2003 & & 2004 & \\
\hline age at inflow in UI & $55.5-57.5$ & $57.5-59.5$ & $\begin{array}{r}\text { 1st jan - } \\
55.5-57.5\end{array}$ & $\begin{array}{l}\text { 10th aug } \\
57.5-59.5\end{array}$ & $55.5-57.5$ & $57.5-59.5$ \\
\hline \multirow[t]{2}{*}{ private sector job } & 3152 & 3476 & 4414 & 3675 & 6270 & 5292 \\
\hline & $(0.83)$ & $(0.86)$ & $(0.85)$ & $(0.88)$ & $(0.86)$ & $(0.87)$ \\
\hline \multirow[t]{2}{*}{ DI benefits } & 596 & 554 & 724 & 480 & 922 & 702 \\
\hline & $(0.16)$ & $(0.14)$ & $(0.14)$ & $(0.11)$ & $(0.13)$ & $(0.12)$ \\
\hline \multirow[t]{2}{*}{ other } & 38 & 25 & 51 & 33 & 95 & 59 \\
\hline & $(0.01)$ & $(0.01)$ & $(0.01)$ & $(0.01)$ & $(0.01)$ & $(0.01)$ \\
\hline TOTAL & 3786 & 4055 & 5189 & 4188 & 7287 & 6053 \\
\hline
\end{tabular}


Table 6. MULTIPLE SPELLS FOR THE SAME INDIVIDUAL

\begin{tabular}{lrr}
\hline & $\begin{array}{r}\text { Number of Persons } \\
\text { (fraction) }\end{array}$ & Number of Spells \\
\hline \hline Observed once & 25806 & 25806 \\
& $(0.93)$ & \\
Observed twice & 1789 & 3579 \\
& $(0.06)$ & \\
Observed three times & 207 & 621 \\
& $(0.01)$ & 48 \\
Observed four times & 12 & 30053 \\
TOTAL & $(0.00)$ & \\
\hline
\end{tabular}

Table 7. IDENTIFICATION REGRESSION 1

turning 57.5,

\begin{tabular}{rrrr} 
& being $<57.5 @$ inflow & being $>57.5 @$ @inflow & being $<57.5 @$ inflow \\
\hline \hline inflow in 2001 & $\mathrm{a}$ & $\mathrm{b}, \gamma_{2}$ & $\mathrm{e}, \gamma_{4}$ \\
inflow in 2004 & $\mathrm{c}, \gamma_{1}$ & $\mathrm{~d}, \gamma_{1}+\gamma_{2}+\gamma_{3}$ & $\mathrm{f}, \gamma_{1}+\gamma_{4}+\gamma_{5}$ \\
\hline & $\mathrm{c}-\mathrm{a}=\gamma_{1}$ & $\mathrm{~d}-\mathrm{b}=\gamma_{3}+\gamma_{1}$ & $\mathrm{f}-\mathrm{e}=\gamma_{1}+\gamma_{5}$ \\
\hline
\end{tabular}

Note: $\gamma_{3}=(\mathrm{d}-\mathrm{b})-(\mathrm{c}-\mathrm{a})$ : effect of needing to search always as opposed to never (age at inflow $>57.5$ )

Note: $\gamma_{5}=(\mathrm{f}-\mathrm{e})-(\mathrm{c}-\mathrm{a})$ : effect of needing to continue search at 57.5 (age at inflow $<57.5$ )

Table 8. IDENTIFICATION REGRESSION 2

till 1 jan 2004, from 1 jan 2004,

being $>57.5 @$ inflow $\quad$ being $>57.5 @$ inflow

\begin{tabular}{rrr}
\hline \hline inflow in 2001 & $\mathrm{a}$ & $\mathrm{b}, \delta_{2}$ \\
inflow in 2003 & $\mathrm{c}, \delta_{1}$ & $\mathrm{~d}, \delta_{1}+\delta_{2}+\delta_{3}$ \\
\hline & $\mathrm{c}-\mathrm{a}=\delta_{1}$ & $\mathrm{~d}-\mathrm{b}=\delta_{1}+\delta_{3}$ \\
\hline
\end{tabular}

Note: $\delta_{3}=(\mathrm{d}-\mathrm{b})-(\mathrm{c}-\mathrm{a})$ : effect of starting to search (@ 1 jan 2004) after

$5-12$ months of unemployment as opposed to never (age at inflow $>57.5$ ) 
Table 9. BACKGROUND CHARACTERSTICS

\begin{tabular}{lrrrrrr} 
year of inflow in UI & 2001 & \multicolumn{3}{c}{2003} \\
age at inflow in UI & $55.5-57.5$ & $57.5-59.5$ & $55.5-57.5$ & $57.5-59.5$ & $55.5-57.5$ & $57.5-59.5$ \\
\hline \hline Age & 56.46 & 58.33 & 56.47 & 58.42 & 56.48 & 58.36 \\
Female & 0.31 & 0.25 & 0.30 & 0.28 & 0.32 & 0.27 \\
Single & 0.08 & 0.06 & 0.09 & 0.06 & 0.08 & 0.07 \\
Married & 0.74 & 0.79 & 0.71 & 0.77 & 0.73 & 0.76 \\
Divorced/widowed & 0.18 & 0.15 & 0.20 & 0.17 & 0.19 & 0.17 \\
Dutch & 0.85 & 0.86 & 0.83 & 0.84 & 0.83 & 0.85 \\
Western & 0.13 & 0.11 & 0.12 & 0.12 & 0.13 & 0.11 \\
Non Western & 0.04 & 0.03 & 0.04 & 0.04 & 0.04 & 0.04 \\
Dependent child & 0.27 & 0.21 & 0.30 & 0.23 & 0.35 & 0.27 \\
Education low & 0.15 & 0.15 & 0.10 & 0.14 & 0.10 & 0.11 \\
Education mid1 & 0.35 & 0.37 & 0.31 & 0.34 & 0.32 & 0.33 \\
Eudcation mid2 & 0.32 & 0.31 & 0.39 & 0.34 & 0.38 & 0.37 \\
Education high & 0.18 & 0.17 & 0.21 & 0.18 & 0.19 & 0.18 \\
Revived UI right & 0.19 & 0.10 & 0.19 & 0.12 & 0.22 & 0.19 \\
short PBD & 0.10 & 0.05 & 0.08 & 0.05 & 0.07 & 0.05 \\
long PBD & 0.87 & 0.92 & 0.89 & 0.92 & 0.91 & 0.93 \\
Monthly UI benefits & 1177 & 1316 & 1267 & 1375 & 1187 & 1269 \\
\# Hours in UI & 32.84 & 33.77 & 32.77 & 33.20 & 32.65 & 33.25 \\
\# Observations & 3152 & 3476 & 4414 & 3675 & 6270 & 5292 \\
\hline No: & & & & &
\end{tabular}

Note: definition of variables is explained in the text

Table 10. EXIT DESTINATIONS (FRACTIONS)

\begin{tabular}{lrrrrrr}
\hline year of inflow in UI & 2001 & & 2003 \\
& & & 1st jan - & 10th aug & & \\
age at inflow in UI & $55.5-57.5$ & $57.5-59.5$ & $55.5-57.5$ & $57.5-59.5$ & $55.5-57.5$ & $57.5-59.5$ \\
\hline \hline Job & 0.48 & 0.32 & 0.40 & 0.28 & 0.43 & 0.31 \\
& $(0.57)$ & $(0.43)$ & $(0.56)$ & $(0.41)$ & $(0.66)$ & $(0.52)$ \\
Retirement & 0.18 & 0.34 & 0.08 & 0.22 & 0.07 & 0.13 \\
& $(0.20)$ & $(0.44)$ & $(0.13)$ & $(0.35)$ & $(0.09)$ & $(0.24)$ \\
DI benefits & 0.17 & 0.09 & 0.14 & 0.10 & 0.09 & 0.08 \\
& $(0.21)$ & $(0.12)$ & $(0.21)$ & $(0.15)$ & $(0.14)$ & $(0.12)$ \\
Censored & 0.17 & 0.25 & 0.38 & 0.40 & 0.41 & 0.48 \\
\# Observations & 3152 & 3476 & 4414 & 3674 & 6270 & 5292 \\
\hline
\end{tabular}

Note: in parentheses: as a fraction of non-censored observations 
Table 11. MEAN AND MEDIAN OF DURATION VARIABLES, DAYS

\begin{tabular}{lcrrrrr}
\hline year of inflow in UI & 2001 & \multicolumn{5}{c}{2003} \\
& & & $\begin{array}{r}1 \text { 1st jan - } \\
\text { 10th aug }\end{array}$ \\
age at inflow in UI & $55.5-57.5$ & $57.5-59.5$ & $55.5-57.5$ & $57.5-59.5$ & $55.5-57.5$ & $57.5-59.5$ \\
\hline \hline Total duration & & & & & & \\
- mean & 525 & 701 & 477 & 544 & 304 & 329 \\
- median & 179 & 455 & 346 & 488 & 252 & 326 \\
to job & & & & & & \\
- mean & 185 & 189 & 238 & 236 & 171 & 158 \\
- median & 109 & 123 & 154 & 183 & 133 & 126 \\
to retirement & & & & & & \\
- mean & 690 & 594 & 252 & 414 & 122 & 209 \\
- median & 639 & 548 & 182 & 371 & 60 & 184 \\
to DI & & & & & & \\
- mean & 238 & 402 & 250 & 334 & 194 & 178 \\
- median & 139 & 272 & 167 & 279 & 161 & 136 \\
\hline
\end{tabular}

Note: all spells (including censored ones at 31st dec 2005) included. 


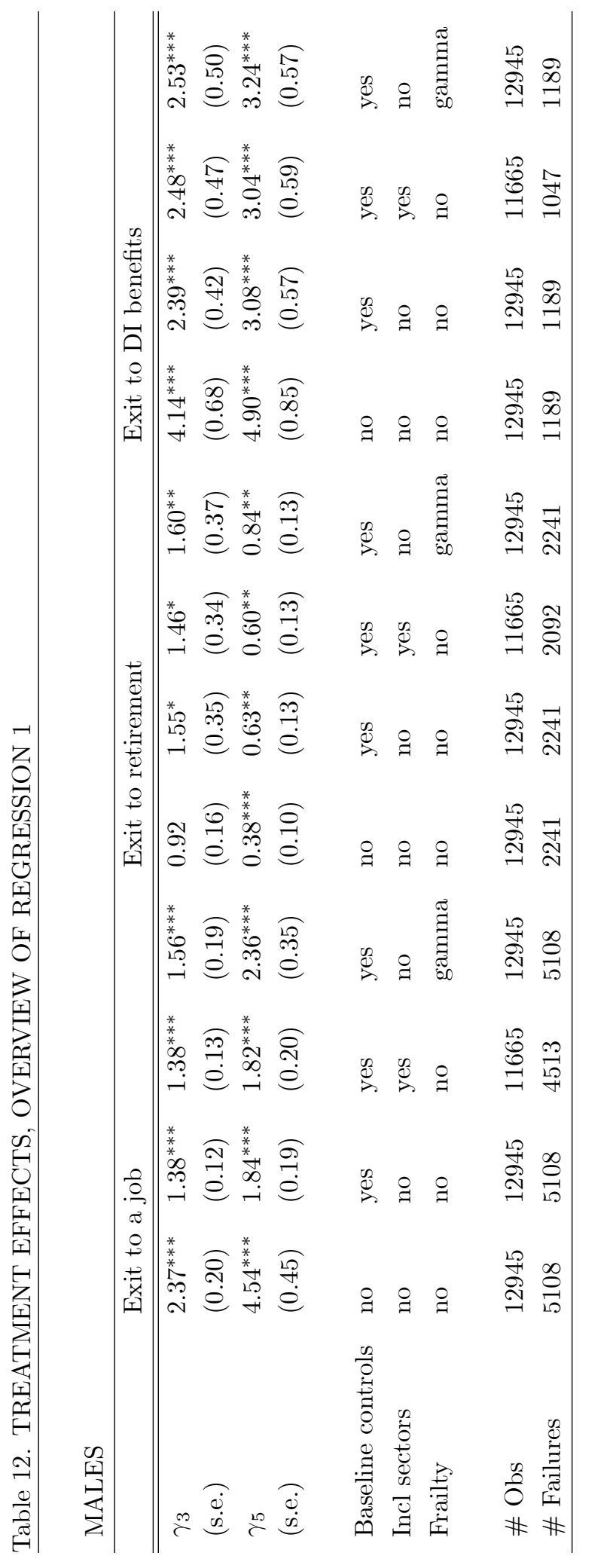

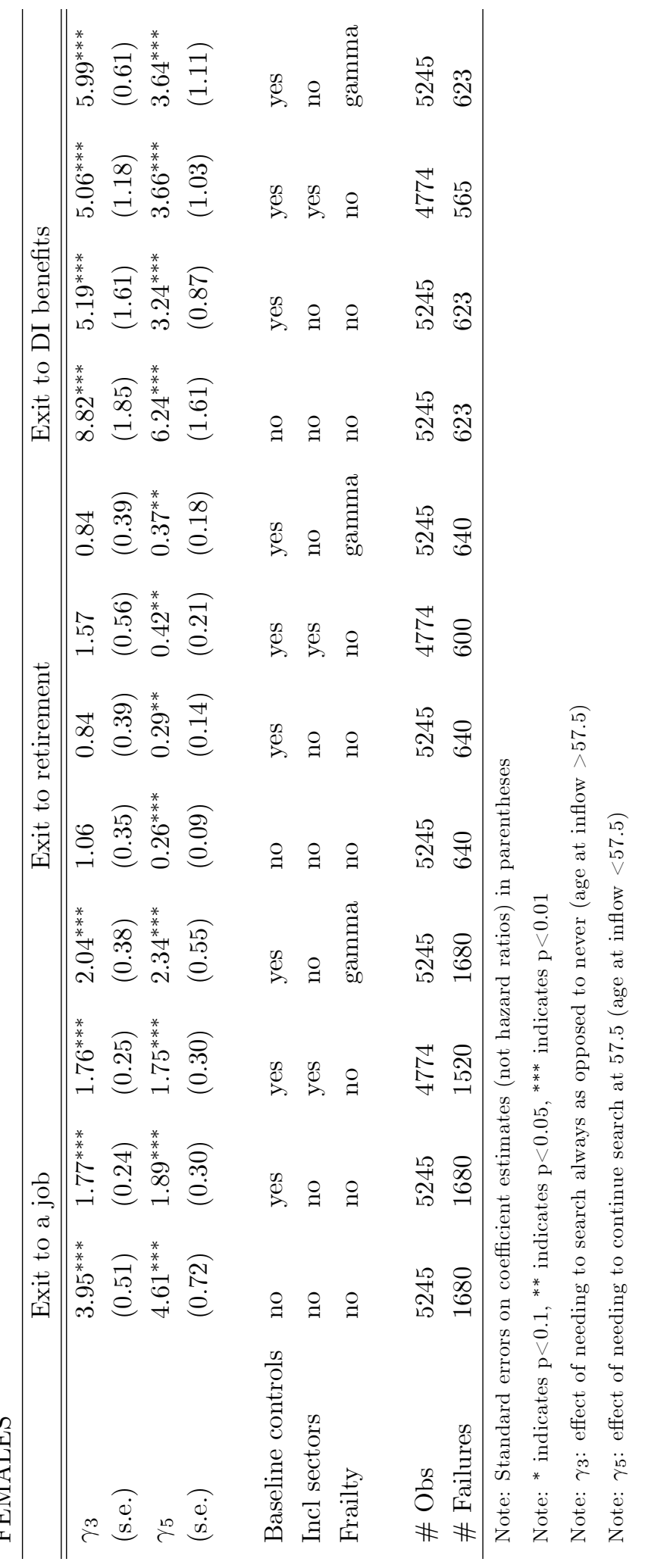




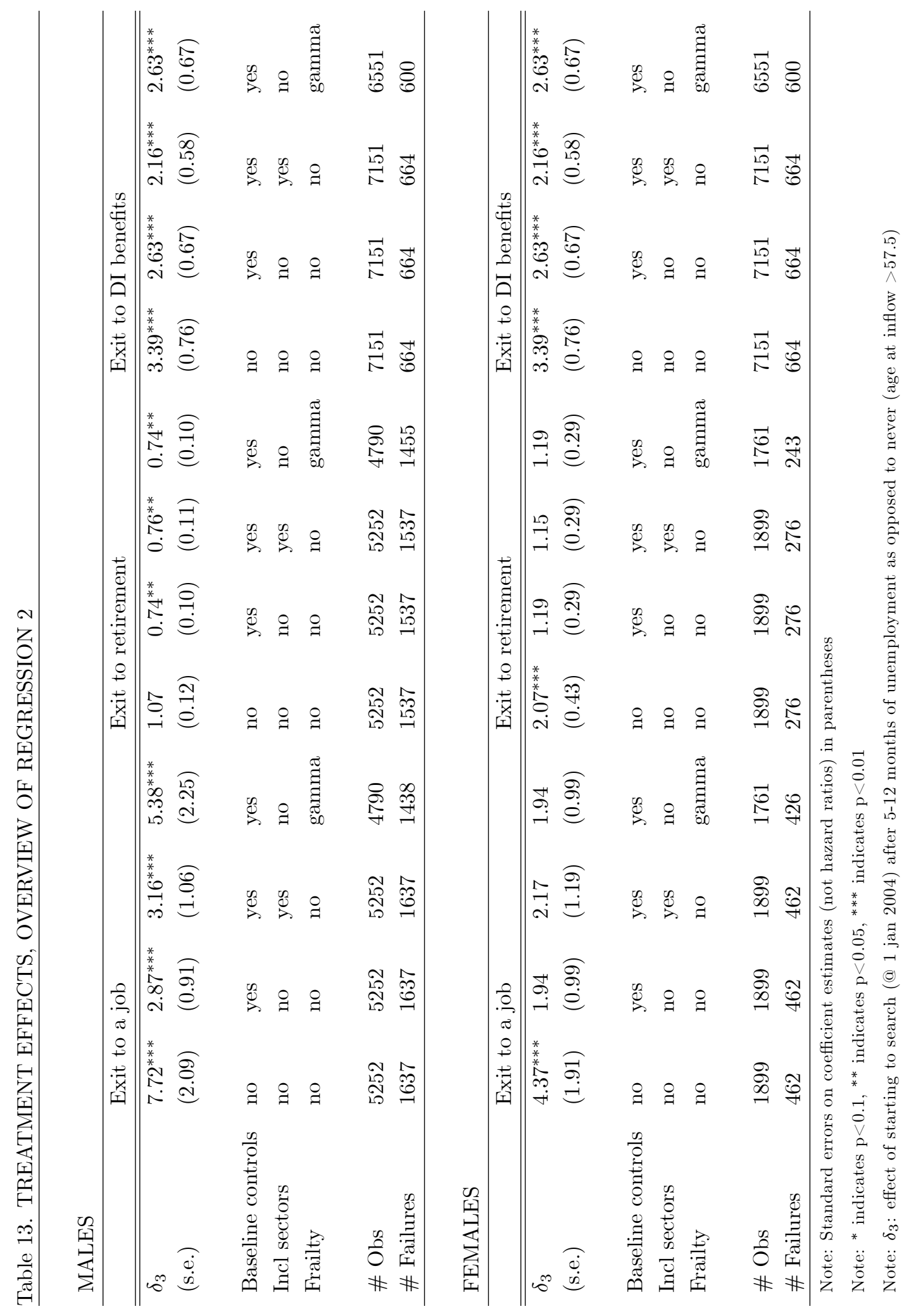


Table 14. TREATMENT EFFECTS, FULL RESULTS REGRESSION 1 - MALES

\begin{tabular}{|c|c|c|c|}
\hline & Exit to a job & Exit to retirement & Exit to DI benefits \\
\hline$\overline{\mathrm{I}^{04}}$ & $0.83^{* * *}$ & $0.80^{*}$ & $0.49^{* * *}$ \\
\hline $\mathrm{I}\left[\mathrm{a}^{I} \geq 57.5\right]$ & $0.56^{* * *}$ & 1.00 & $0.36^{* * *}$ \\
\hline $\mathrm{I}\left[\mathrm{a}^{I} \geq 57.5\right]^{*} \mathrm{I}^{04}-\gamma_{3}$ & $1.38^{* * *}$ & $1.55^{*}$ & $2.39^{* * *}$ \\
\hline $\mathrm{I}\left[\mathrm{a}_{\tau} \geq 57.5\right]$ & $0.59^{* * *}$ & 1.20 & $0.44^{* * *}$ \\
\hline $\mathrm{I}\left[\mathrm{a}_{\tau} \geq 57.5\right]^{*} \mathrm{I}^{04}-\gamma_{5}$ & $1.84^{* * *}$ & 0.81 & $3.08^{* * *}$ \\
\hline$\gamma_{3} *$ married & 0.97 & 0.91 & 0.92 \\
\hline married & 1.03 & $1.38^{* * *}$ & $0.80^{* * *}$ \\
\hline age & $0.80^{* * *}$ & & 0.82 \\
\hline $\operatorname{age}^{2}$ & $1.04^{* * *}$ & & $1.05^{*}$ \\
\hline west & 1.07 & $0.85^{* *}$ & 0.95 \\
\hline non-west & $0.77^{* * *}$ & 0.89 & $1.41^{* * *}$ \\
\hline kid & $1.26^{* * *}$ & 0.93 & $1.16^{* *}$ \\
\hline educ2 & 1.02 & 1.13 & 0.97 \\
\hline educ3 & 1.03 & $1.36^{* * *}$ & $0.83^{* *}$ \\
\hline educ4 & $0.87^{* * *}$ & $1.62^{* * *}$ & $0.59^{* * *}$ \\
\hline revived & $1.12^{* * *}$ & $0.53^{* * *}$ & $1.24^{* * *}$ \\
\hline long PBD & $0.59^{* * *}$ & $4.07^{* * *}$ & 1.27 \\
\hline unknown PBD & 0.89 & $1.73^{*}$ & 0.94 \\
\hline quarter2 & $0.82^{* * *}$ & $0.29^{* * *}$ & $0.54^{* * *}$ \\
\hline quarter3 & $0.48^{* * *}$ & $0.28^{* * *}$ & $0.62^{* * *}$ \\
\hline quarter4 & $0.27^{* * *}$ & $0.25^{* * *}$ & $0.42^{* * *}$ \\
\hline $\mathrm{I}_{2}$ & $1.73^{* * *}$ & 1.10 & 0.91 \\
\hline $\mathrm{I}_{3}$ & $1.98^{* * *}$ & $0.66^{* * *}$ & 0.93 \\
\hline $\mathrm{I}_{4}$ & $2.14^{* * *}$ & $0.47^{* * *}$ & 0.92 \\
\hline $\mathrm{I}_{5}$ & 0.97 & $0.49^{* * *}$ & $0.74^{* * *}$ \\
\hline $\mathrm{I}_{6}$ & $0.43^{* * *}$ & $0.45^{* * *}$ & $0.45^{* * *}$ \\
\hline $\mathrm{I}_{7}$ & $0.09^{* * *}$ & $0.35^{* * *}$ & $0.26^{* * *}$ \\
\hline $\mathrm{I}\left[\geq 56.5 \mathrm{a}_{\tau} \geq 57.5\right]$ & & 1.00 & \\
\hline $\mathrm{I}\left[\geq 57.5 \mathrm{a}_{\tau} \geq 58.5\right]$ & & 1.09 & \\
\hline $\mathrm{I}\left[\geq 58.5 \mathrm{a}_{\tau} \geq 59.5\right]$ & & 0.99 & \\
\hline $\mathrm{I}\left[\geq 59.5 \mathrm{a}_{\tau} \geq 60.5\right]$ & & $2.80^{* * *}$ & \\
\hline $\mathrm{I}\left[\geq 60.5 \mathrm{a}_{\tau} \geq 61.5\right]$ & & $1.71^{* * *}$ & \\
\hline $\mathrm{I}\left[\geq 61.5 \mathrm{a}_{\tau} \geq 62.5\right]$ & & $2.67^{* * *}$ & \\
\hline $\mathrm{I}\left[\geq 62.5 \mathrm{a}_{\tau} \geq 63.5\right]$ & & 1.21 & \\
\hline $\mathrm{I}\left[\geq 62.5 \mathrm{a}_{\tau} \geq 63.5\right]$ & & 0.00 & \\
\hline $\mathrm{I}\left[\geq 56.5 \mathrm{a}_{\tau} \geq 57.5\right]^{*} \mathrm{I}^{04}$ & & 0.84 & \\
\hline $\mathrm{I}\left[\geq 57.5 \mathrm{a}_{\tau} \geq 58.5\right]^{*} \mathrm{I}^{04}$ & & $0.63^{* *}$ & \\
\hline $\mathrm{I}\left[\geq 58.5 \mathrm{a}_{\tau} \geq 59.5\right]^{*} \mathrm{I}^{04}$ & & 0.79 & \\
\hline $\mathrm{I}\left[\geq 59.5 \mathrm{a}_{\tau} \geq 60.5\right]^{*} \mathrm{I}^{04}$ & & $0.69^{* *}$ & \\
\hline $\mathrm{I}\left[\geq 60.5 \mathrm{a}_{\tau} \geq 61.5\right]^{*} \mathrm{I}^{04}$ & & $0.46^{*}$ & \\
\hline \# Obs & 12945 & 12945 & 12945 \\
\hline \# Failures & 5108 & 2241 & 1189 \\
\hline \multicolumn{4}{|c|}{ Note: ${ }^{*}$ indicates $\mathrm{p}<0.1,{ }^{* *}$ indicates $\mathrm{p}<0.05,{ }^{* * *}$ indicates $\mathrm{p}<0.01$} \\
\hline Note: $\gamma_{3}$ : effect of ne & ding to search & lways as opposed to & ever (age at inflow $>57.5$ ) \\
\hline Note: $\gamma_{5}:$ effect of ne & ding to continu & search at 57.5 (age & t inflow $<57.5)$ \\
\hline
\end{tabular}


Table 15. TREATMENT EFFECTS, FULL RESULTS REGRESSION 1 - FEMALES

\begin{tabular}{|c|c|c|c|}
\hline & Exit to a job & Exit to retirement & Exit to DI benefits \\
\hline$\overline{\mathrm{I}^{04}}$ & $0.72^{* * *}$ & 1.25 & $0.39^{* * *}$ \\
\hline $\mathrm{I}\left[\mathrm{a}^{I} \geq 57.5\right]$ & $0.45^{* * *}$ & 1.43 & $0.21^{* * *}$ \\
\hline $\mathrm{I}\left[\mathrm{a}^{I} \geq 57.5\right]^{*} \mathrm{I}^{04}-\gamma_{3}$ & $1.77^{* * *}$ & 0.84 & $5.19^{* * *}$ \\
\hline $\mathrm{I}\left[\mathrm{a}_{\tau} \geq 57.5\right]$ & $0.57^{* * *}$ & 1.43 & $0.25^{* * *}$ \\
\hline $\mathrm{I}\left[\mathrm{a}_{\tau} \geq 57.5\right]^{*} \mathrm{I}^{04}-\gamma_{5}$ & $1.89^{* * *}$ & 0.50 & $3.24^{* * *}$ \\
\hline$\gamma_{3}{ }^{*}$ married & 0.97 & 1.09 & 0.72 \\
\hline married & $0.85^{* * *}$ & $0.67^{* * *}$ & 0.93 \\
\hline age & $0.78^{* *}$ & & 0.96 \\
\hline $\operatorname{age}^{2}$ & $1.04^{*}$ & & 0.99 \\
\hline west & 0.96 & 1.03 & 1.19 \\
\hline non-west & 1.18 & 0.90 & 1.33 \\
\hline kid & $1.24^{* * *}$ & 1.05 & $1.20^{*}$ \\
\hline educ2 & 1.07 & 1.09 & 0.95 \\
\hline educ3 & $1.22^{* *}$ & $1.40^{* *}$ & 0.92 \\
\hline educ4 & $1.34^{* * *}$ & $2.25^{* * *}$ & $0.73^{*}$ \\
\hline revived & $1.17^{* * *}$ & $0.74^{* * *}$ & 1.00 \\
\hline long PBD & $0.53^{* * *}$ & $2.62^{* * *}$ & 1.03 \\
\hline unknown PBD & 0.95 & 1.38 & 1.15 \\
\hline quarter2 & $0.61^{* * *}$ & $0.53^{* * *}$ & $0.44^{* * *}$ \\
\hline quarter3 & $0.57^{* * *}$ & $0.44^{* * *}$ & $0.51^{* * *}$ \\
\hline quarter4 & $0.37^{* * *}$ & $0.39^{* * *}$ & $0.42^{* * *}$ \\
\hline $\mathrm{I}_{2}$ & $1.77^{* * *}$ & 0.95 & 0.99 \\
\hline $\mathrm{I}_{3}$ & $1.62^{* * *}$ & $0.61^{* *}$ & $1.84^{* * *}$ \\
\hline $\mathrm{I}_{4}$ & $2.08^{* * *}$ & 0.43 & $1.66^{* * *}$ \\
\hline $\mathrm{I}_{5}$ & 1.13 & $0.50^{* * *}$ & 1.25 \\
\hline $\mathrm{I}_{6}$ & $0.45^{* * *}$ & $0.41^{* * *}$ & 0.76 \\
\hline $\mathrm{I}_{7}$ & $0.10^{* * *}$ & $0.39^{* * *}$ & $0.22^{* * *}$ \\
\hline $\mathrm{I}\left[\geq 56.5 \mathrm{a}_{\tau} \geq 57.5\right]$ & & 0.50 & \\
\hline $\mathrm{I}\left[\geq 57.5 \mathrm{a}_{\tau} \geq 58.5\right]$ & & 1.52 & \\
\hline $\mathrm{I}\left[\geq 58.5 \mathrm{a}_{\tau} \geq 59.5\right]$ & & 0.89 & \\
\hline $\mathrm{I}\left[\geq 59.5 \mathrm{a}_{\tau} \geq 60.5\right]$ & & $6.09^{* * *}$ & \\
\hline $\mathrm{I}\left[\geq 60.5 \mathrm{a}_{\tau} \geq 61.5\right]$ & & $2.01^{* *}$ & \\
\hline $\mathrm{I}\left[\geq 61.5 \mathrm{a}_{\tau} \geq 62.5\right]$ & & $2.71^{* * *}$ & \\
\hline $\mathrm{I}\left[\geq 62.5 \mathrm{a}_{\tau} \geq 63.5\right]$ & & 1.38 & \\
\hline $\mathrm{I}\left[\geq 63.5 \mathrm{a}_{\tau} \geq 64.5\right]$ & & 1.93 & \\
\hline $\mathrm{I}\left[\geq 56.5 \mathrm{a}_{\tau} \geq 57.5\right]^{*} \mathrm{I}^{04}$ & & 1.49 & \\
\hline $\mathrm{I}\left[\geq 57.5 \mathrm{a}_{\tau} \geq 58.5\right]^{*} \mathrm{I}^{04}$ & & $0.29^{* *}$ & \\
\hline $\mathrm{I}\left[\geq 58.5 \mathrm{a}_{\tau} \geq 59.5\right]^{*} \mathrm{I}^{04}$ & & 0.66 & \\
\hline $\mathrm{I}\left[\geq 59.5 \mathrm{a}_{\tau} \geq 60.5\right]^{*} \mathrm{I}^{04}$ & & 0.67 & \\
\hline $\mathrm{I}\left[\geq 60.5 \mathrm{a}_{\tau} \geq 61.5\right]^{*} \mathrm{I}^{04}$ & & 1.46 & \\
\hline \# Obs & 5245 & 5245 & 5245 \\
\hline \# Failures & 1680 & 640 & 623 \\
\hline
\end{tabular}

Note: ${ }^{*}$ indicates $\mathrm{p}<0.1,{ }^{* *}$ indicates $\mathrm{p}<0.05,{ }^{* * *}$ indicates $\mathrm{p}<0.01$

Note: $\gamma_{3}$ : effect of needing to search always as opposed to never (age at inflow $>57.5$ )

Note: $\gamma_{5}$ : effect of needing to continue search at 57.5 (age at inflow $<57.5$ )

A description of regressors can be found in the main text 
Table 16. TREATMENT EFFECTS, FULL RESULTS REGRESSION 2 - MALES

\begin{tabular}{llll}
\hline & Exit to a job & Exit to retirement & Exit to DI benefits \\
\hline \hline $\mathrm{I}^{03}$ & 0.97 & $1.62^{* * *}$ & $1.27^{* *}$ \\
$\mathrm{I}[\tau \geq 1$ Jan 2004] & $0.22^{* * *}$ & $0.43^{* * *}$ & $0.33^{* * *}$ \\
$\mathrm{I}^{03 *} \mathrm{I}\left[\tau \geq 1\right.$ Jan 2004] $-\delta_{3}$ & $2.87^{* * *}$ & $0.74^{* *}$ & $2.63^{* * *}$ \\
married & 1.00 & $1.22^{* * *}$ & $0.84^{*}$ \\
age & 2.20 & 1.40 & 3.57 \\
age & 0.91 & 0.99 & 0.84 \\
west & 1.03 & 0.92 & 0.83 \\
non-west & 0.93 & 0.93 & 1.29 \\
kid & $1.34^{* * *}$ & 1.04 & 1.05 \\
educ2 & 1.02 & $1.18^{*}$ & 0.91 \\
educ3 & 0.90 & $1.32^{* * *}$ & 0.93 \\
educ4 & $0.82^{* *}$ & $1.72^{* * *}$ & $0.67^{* * *}$ \\
revived & $1.18^{* * *}$ & $0.58^{* * *}$ & $1.37^{* * *}$ \\
long PBD & $0.50^{* * *}$ & $2.92^{* * *}$ & 1.06 \\
unknown PBD & 1.15 & 1.64 & 1.55 \\
quarter2 & $0.59^{* * *}$ & $0.27^{* * *}$ & $0.43^{* * *}$ \\
quarter3 & $0.35^{* * *}$ & $0.24^{* * *}$ & $0.45^{* * *}$ \\
quarter4 & $0.16^{* * *}$ & $0.21^{* * *}$ & $0.27^{* * *}$ \\
$\mathrm{I}_{2}$ & $1.80^{* * *}$ & $0.66^{* * *}$ & 0.72 \\
$\mathrm{I}_{3}$ & $2.24^{* * *}$ & $0.69^{* *}$ & 1.03 \\
$\mathrm{I}_{4}$ & $2.34^{* * *}$ & $0.73^{* *}$ & 1.33 \\
$\mathrm{I}_{5}$ & $1.21^{*}$ & 0.93 & 1.07 \\
$\mathrm{I}_{6}$ & $0.54^{* * *}$ & $1.48^{* * *}$ & 0.77 \\
$\mathrm{I}_{7}$ & $0.22^{* * *}$ & $1.80^{* * *}$ & $0.67^{*}$ \\
& & & \\
$\#$ Obs & 5252 & 5252 & 7151 \\
\# Failures & 1637 & 1537 & 664 \\
\hline
\end{tabular}

Note: ${ }^{*}$ indicates $\mathrm{p}<0.1,{ }^{* *}$ indicates $\mathrm{p}<0.05,{ }^{* * *}$ indicates $\mathrm{p}<0.01$

Note: $\delta_{3}$ : effect of starting to search (@ 1 jan 2004) after 5-12 months of unemployment as opposed to never (age at inflow $>57.5$ )

A description of regressors can be found in the main text 
Table 17. TREATMENT EFFECTS, FULL RESULTS REGRESSION 2 - FEMALES

\begin{tabular}{|c|c|c|c|}
\hline & Exit to a job & Exit to retirement & Exit to DI benefits \\
\hline$\overline{\mathrm{I}^{03}}$ & $1.46^{* * *}$ & " 1.22 & " $1.27^{* *}$ \\
\hline $\mathrm{I}[\tau \geq 1$ Jan 2004$]$ & $0.22^{* * *}$ & $0.44^{* * *}$ & $0.33^{* * *}$ \\
\hline $\mathrm{I}^{03 *} \mathrm{I}[\tau \geq 1$ Jan 2004$]-\delta_{3}$ & 1.94 & 1.19 & $2.63^{* * *}$ \\
\hline married & 0.87 & $0.67^{* * *}$ & $0.84^{*}$ \\
\hline age & 1.62 & 1.95 & 3.57 \\
\hline $\operatorname{age}^{2}$ & 0.94 & 0.94 & 0.84 \\
\hline west & $0.77^{*}$ & 0.93 & 0.83 \\
\hline non-west & $1.57^{* * *}$ & 0.97 & 1.29 \\
\hline kid & 0.98 & 0.94 & 1.05 \\
\hline educ2 & 0.93 & 1.19 & 0.91 \\
\hline educ3 & 1.07 & $1.48^{* *}$ & 0.93 \\
\hline educ4 & $1.67^{* * *}$ & $2.25^{* * *}$ & $0.67^{* * *}$ \\
\hline revived & $1.57^{* * *}$ & 0.90 & $1.37^{* * *}$ \\
\hline long PBD & $0.37^{* * *}$ & $2.10^{* * *}$ & 1.06 \\
\hline unknown PBD & $0.52^{* * *}$ & 0.80 & 1.55 \\
\hline quarter2 & $0.38^{* * *}$ & $0.53^{* * *}$ & $0.43^{* * *}$ \\
\hline quarter3 & $0.34^{* * *}$ & $0.41^{* * *}$ & $0.45^{* * *}$ \\
\hline quarter4 & $0.18^{* * *}$ & $0.39^{* * *}$ & $0.27^{* * *}$ \\
\hline $\mathrm{I}_{2}$ & $1.56^{*}$ & 0.85 & 0.72 \\
\hline $\mathrm{I}_{3}$ & $2.73^{* * *}$ & 1.14 & 1.03 \\
\hline $\mathrm{I}_{4}$ & $4.19^{* * *}$ & 0.85 & 1.33 \\
\hline $\mathrm{I}_{5}$ & $2.31^{* * *}$ & 1.35 & 1.07 \\
\hline $\mathrm{I}_{6}$ & 0.72 & $2.48^{* * *}$ & 0.77 \\
\hline $\mathrm{I}_{7}$ & $0.45^{* * *}$ & $2.70^{* * *}$ & $0.67^{*}$ \\
\hline \# Obs & 1899 & 1899 & 7151 \\
\hline \# Failures & 462 & 476 & 664 \\
\hline
\end{tabular}

Note: ${ }^{*}$ indicates $\mathrm{p}<0.1,{ }^{* *}$ indicates $\mathrm{p}<0.05,{ }^{* * *}$ indicates $\mathrm{p}<0.01$

Note: $\delta_{3}$ : effect of starting to search (@ 1 jan 2004) after 5-12 months of unemployment as opposed to never (age at inflow $>57.5$ )

A description of regressors can be found in the main text 


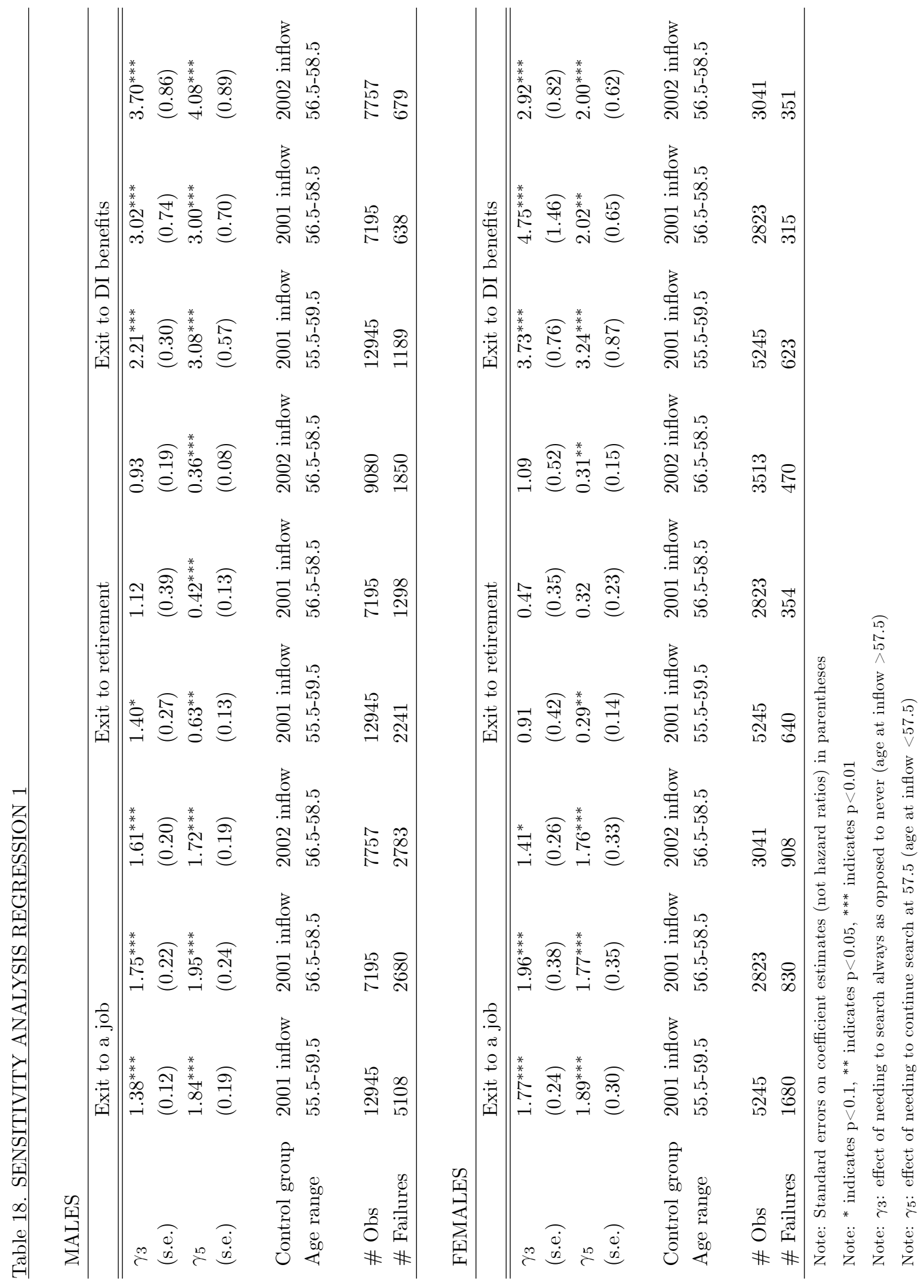




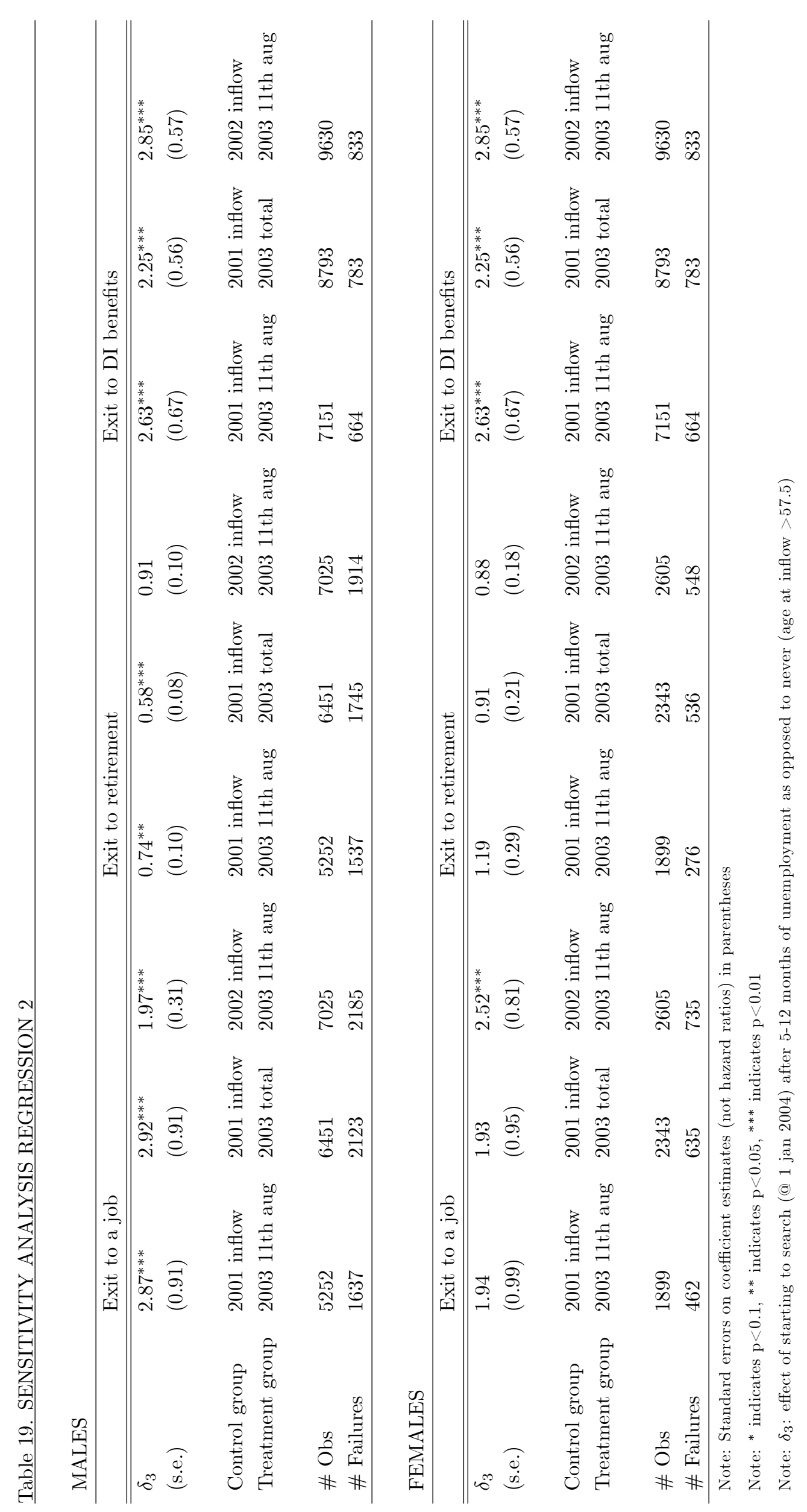


Table 20. MULTIVARIATE MIXED PROPORTIONAL HAZARD MODEL

\section{REGRESSION 1}

\begin{tabular}{llll} 
MALES & & & \\
\hline & exit to a job & exit to retirement & exit to DI benefits \\
\hline \hline$\gamma_{3}$ & $1.40^{* * *}$ & $1.43^{*}$ & $2.27^{* * *}$ \\
$($ s.e. $)$ & $(0.07)$ & $(0.19)$ & $(0.13)$ \\
$\gamma_{5}$ & $1.88^{* * *}$ & $0.58^{* *}$ & $3.07^{* * *}$ \\
(s.e.) & $(0.12)$ & $(0.21)$ & $(0.19)$ \\
$\#$ Obs & 12945 & 12945 & 12945 \\
\hline
\end{tabular}

FEMALES

\begin{tabular}{llll}
\hline & exit to a job & exit to retirement & exit to DI benefits \\
\hline \hline$\gamma_{3}$ & $1.98^{* * *}$ & 0.83 & $4.42^{* * *}$ \\
$($ s.e. $)$ & $(0.14)$ & $(0.45)$ & $(0.19)$ \\
$\gamma_{5}$ & $1.95^{* * *}$ & $0.25^{* * *}$ & $3.13^{* * *}$ \\
(s.e.) & $(0.19)$ & $(0.48)$ & $(0.28)$ \\
$\#$ Obs & 5245 & 5245 & 5245 \\
\hline
\end{tabular}

\section{REGRESSION 2}

\begin{tabular}{|c|c|c|c|}
\hline & exit to a job & exit to retirement & exit to DI benefits \\
\hline$\delta_{3}$ & $3.58^{* * *}$ & $0.73^{* * *}$ & $3.02^{* * *}$ \\
\hline (s.e.) & $(0.33)$ & $(0.13)$ & $(0.30)$ \\
\hline \# Obs & 5252 & 5252 & 5252 \\
\hline
\end{tabular}

FEMALES

\begin{tabular}{llll}
\hline & exit to a job & exit to retirement & exit to DI benefits \\
\hline \hline$\delta_{3}$ & 2.37 & 1.06 & 1.93 \\
(s.e.) & $(0.62)$ & $(0.23)$ & $(0.52)$ \\
\# Obs & 1899 & 1899 & 1899 \\
\hline
\end{tabular}

Note: Standard errors on coefficient estimates (not hazard ratios) in parentheses

Note: ${ }^{*}$ indicates $\mathrm{p}<0.1,{ }^{* *}$ indicates $\mathrm{p}<0.05,{ }^{* * *}$ indicates $\mathrm{p}<0.01$

Note: $\gamma_{3}$ : effect of needing to search always as opposed to never (age at inflow $>57.5$ )

Note: $\gamma_{5}$ : effect of needing to continue search at 57.5 (age at inflow $<57.5$ )

Note: $\delta_{3}$ : effect of starting to search (@ 1 jan 2004) after 5-12 months of unemployment (age at inflow $>57.5$ )

Results on females for regression 2 are estimated under the assumption of no heterogeneity in retirement behavior, since without restrictions the heterogeneity terms in the retirement equation would converge to the same point. 


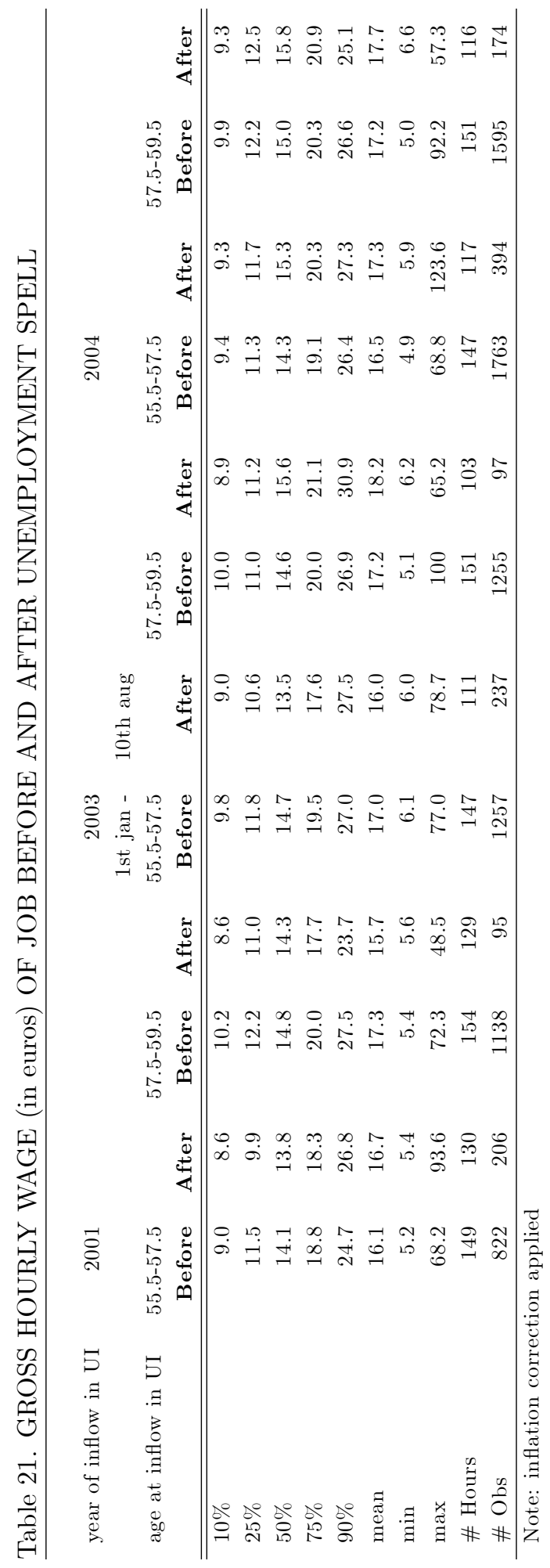


Table 22. TYPE OF WORK BEFORE AND AFTER UNEMPLOYMENT SPELL

\begin{tabular}{lrrrrrr} 
year of inflow in UI & 2001 & \multicolumn{5}{c}{$\begin{array}{r}2003 \\
\text { 1st jan - }\end{array}$} \\
& & & 10th aug & & \\
age at inflow in UI & $55.5-57.5$ & $57.5-59.5$ & $55.5-57.5$ & $57.5-59.5$ & $55.5-57.5$ & $57.5-59.5$ \\
\hline \hline Before & & & & & & \\
Parttime & 0.22 & 0.17 & 0.29 & 0.27 & 0.31 & 0.27 \\
Fulltime & 0.65 & 0.73 & 0.57 & 0.62 & 0.55 & 0.61 \\
Flex & 0.13 & 0.09 & 0.14 & 0.11 & 0.15 & 0.12 \\
\# Observations & 1445 & 1615 & 2833 & 2195 & 4395 & 3461 \\
After & & & & & & \\
Parttime & 0.34 & 0.38 & 0.36 & 0.45 & 0.33 & 0.35 \\
Fulltime & 0.45 & 0.45 & 0.37 & 0.32 & 0.37 & 0.40 \\
Flex & 0.21 & 0.17 & 0.28 & 0.23 & 0.31 & 0.25 \\
\# Observations & 1642 & 1170 & 1901 & 1044 & 2791 & 1678 \\
\hline
\end{tabular}

Note: numbers given as a fraction of the number of individuals for whom we observe whether they went to parttime, fulltime of flextime unemployment. That is, the total fraction of individuals in the three employment types should add up to 1 for each group (apart from effects of rounding). 